\title{
Vulture flight behavior driven by uplift availability at local and continental scales
}

Julie Mallon

Follow this and additional works at: https://researchrepository.wvu.edu/etd

\section{Recommended Citation}

Mallon, Julie, "Vulture flight behavior driven by uplift availability at local and continental scales" (2015). Graduate Theses, Dissertations, and Problem Reports. 6149.

https://researchrepository.wvu.edu/etd/6149

This Thesis is protected by copyright and/or related rights. It has been brought to you by the The Research Repository @ WVU with permission from the rights-holder(s). You are free to use this Thesis in any way that is permitted by the copyright and related rights legislation that applies to your use. For other uses you must obtain permission from the rights-holder(s) directly, unless additional rights are indicated by a Creative Commons license in the record and/ or on the work itself. This Thesis has been accepted for inclusion in WVU Graduate Theses, Dissertations, and Problem Reports collection by an authorized administrator of The Research Repository @ WVU. For more information, please contact researchrepository@mail.wvu.edu. 


\title{
VULTURE FLIGHT BEHAVIOR DRIVEN BY UPLIFT AVAILABILITY AT LOCAL AND CONTINENTAL SCALES
}

\author{
by \\ Julie Mallon \\ Thesis submitted \\ to the Davis College of Agriculture, Natural Resources and Design \\ at West Virginia University \\ in partial fulfillment of the requirements \\ for the degree of \\ Master of Science \\ in \\ Forestry and Natural Resources
}

\author{
Approved by \\ Michael Strager, Ph.D. \\ Todd Katzner, Ph.D., Chair \\ Eungul Lee, Ph.D. \\ Keith Bildstein, Ph.D. \\ Department of Wildlife and Fisheries Resources \\ Morgantown, West Virginia \\ 2015 \\ Keywords: movement, ecology, flight, behavior, soaring, uplift, \\ updrafts, New World Vultures, Cathartes aura, Coragyps atratus, \\ resource use, global scale, altitude \\ Copyright 2015 Julie Mallon
}




\title{
Abstract \\ VULTURE FLIGHT BEHAVIOR DRIVEN BY UPLIFT AVAILABILITY AT LOCAL AND CONTINENTAL SCALES
}

\author{
by Julie Mallon
}

Understanding how animals move in response to their environment is a fundamental question in ecology. Soaring species, which rely on environmentally generated uplift to forage and migrate, should be especially sensitive to changing weather and climatic conditions. Changes in uplift distribution or strength can have energetic implications and restrict movement capacity for soaring species. Poor weather conditions can shorten foraging time or slow migration progress. To increase mobility, birds can switch to flapping or soar using another uplift type. Use of uplift, however, is associated with certain flight altitudes and movement speeds. Switching uplift types will affect a bird's ecological interactions and how it moves through its environment. Understanding how species flight behavior is affected by variable conditions, therefore, informs how species movements change under varied environmental conditions.

Numerous studies have evaluated avian behavioral and movement responses to environmental variation. The greatest focus of these studies has been of migration movements. Yet, it is also important to study such responses during non-migratory periods; movements during the breeding and non-breeding seasons affect an individual's foraging behavior and inter-specific interactions.

To better understand how soaring species behaved under variable conditions, I observed flight behavior at local- and continental-scales. I first evaluated variation in flight behavior of black (Coragyps atratus) and turkey (Cathartes aura) vultures in response to variation in environmental conditions during the breeding season. I then evaluated the relationship between flight behavior and uplift availability at a continental-scale during the breeding and nonbreeding seasons.

At the local-scale, I found uplift type use influenced flight behavior and species selected uplift resources differently under the same conditions. At the global-scale, I found that flight behavior again was driven by the uplift available, as turkey vultures exhibited variable flight patterns when multiple uplift types were available but exhibited a more singular flight pattern when only one uplift type was available. My local-scale observations documented the use of a previously unidentified uplift type to soar, which is likely used by other soaring species. I also documented behavioral response to climate-scale variation in uplift availability. Different responses to uplift availability by black and turkey vultures suggest that 
sympatry of these species may occur because they have species-specific flight strategies. Species-specific flight strategies should cause vultures to select certain carrion types, thereby diffusing competition for carrion resources. My findings suggest the functional roles of vultures as scavengers is ultimately linked to their movement behavior. 


\section{ACKNOWLEDGMENTS}

Co-authors contributed in the following ways: J. Mallon wrote the manuscripts and conducted field research under the direction of T. Katzner. J. Mallon collected data for chapter one. K. Bildstein and Hawk Mountain Sanctuary provided data for chapter 2. Hawk Mountain Sanctuary and the Burket-Plack Foundation provided funding for this project.

Committee members M. Strager and E. Lee advised on technical writing and analysis. J. Fallon provided instruction on handling and bleeding birds. D. Barber maintained data used in our analyses.

Field technicians K. Fagan and P. Philips provided excellent assistance in the field. J. Cooper and E. Frank trapped and deployed telemetry units on black and turkey vultures in Virginia. Virginia DGIF and New Kent Forestry Center provided housing during our field seasons. I thank L. Stiffler and S. Coster and family for providing respite after long days in the field.

I especially thank members of the Katzner lab: D. Hartman, T. Miller, A. Duerr, J. Hall, S. Coster, M. Wheeler, C. Concepcion, M. Jensen, A. Dennhardt, C. Slover, M. Paulson, L. Stiffler, S. Behmke, B. Drahota, J. Daniel, M. Braham for all of their support and encouragement, plus many hours of entertainment. 
TABLE OF CONTENTS

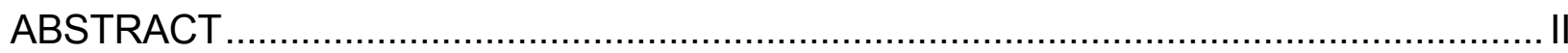

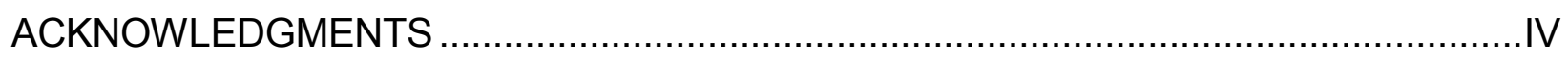

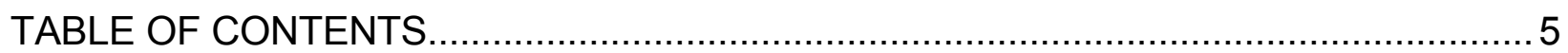

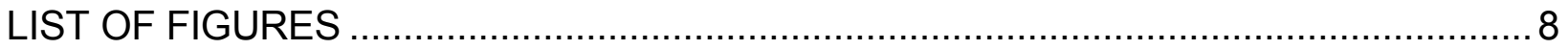

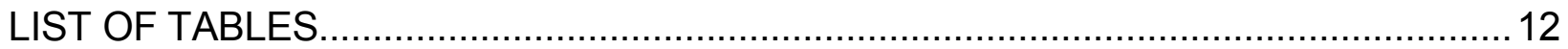

CHAPTER 1 IN-FLIGHT TURBULENCE BENEFITS SOARING BIRDS .......................13

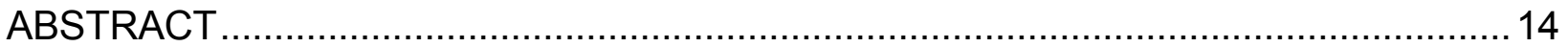

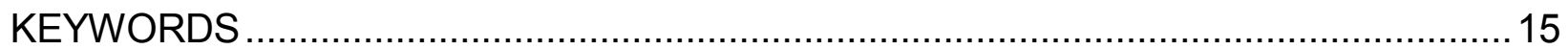

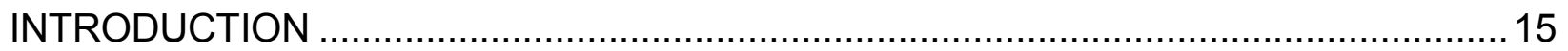

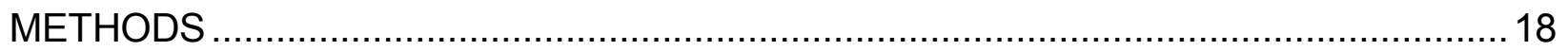

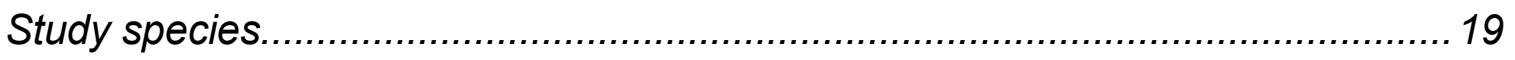

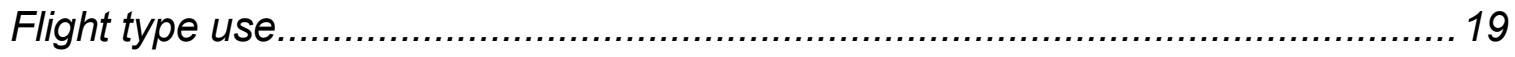

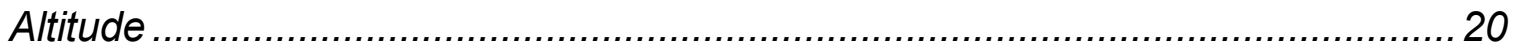

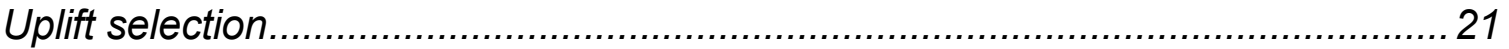

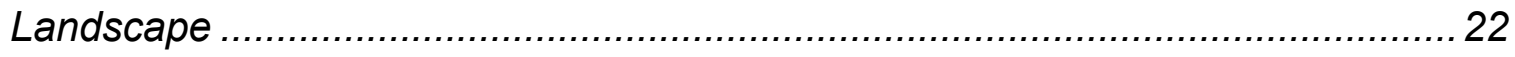

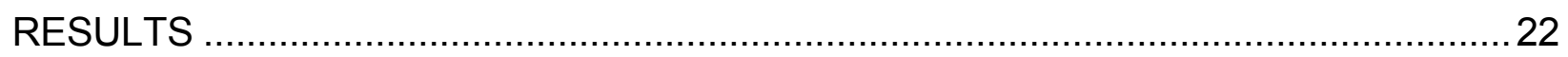

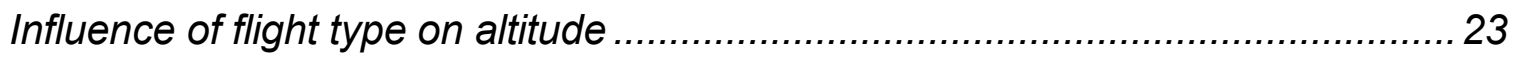

Weather conditions influence flight type use ....................................................... 25

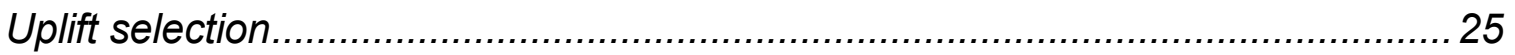

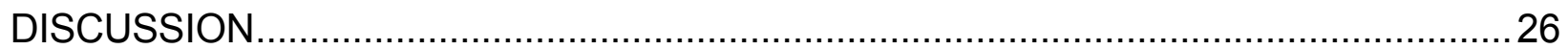

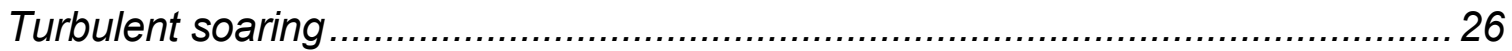

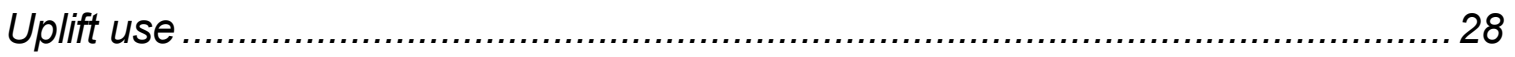

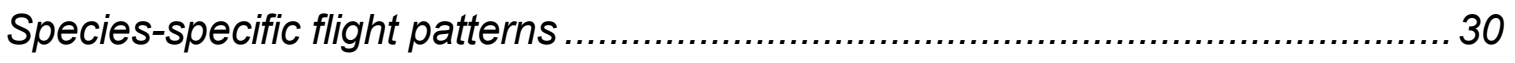


CONCLUSION.

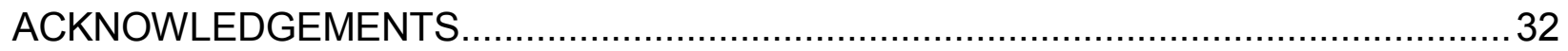

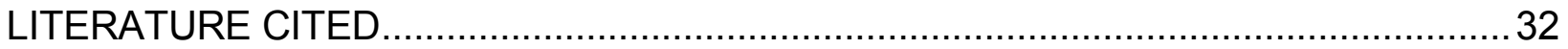

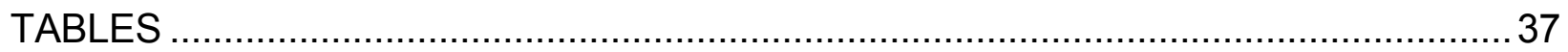

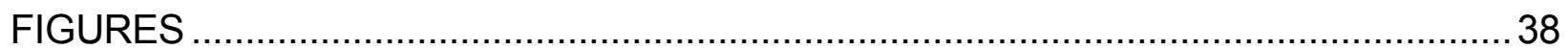

CHAPTER 2 CONTINENTAL SCALE RESPONSE TO VARIATION IN UPLIFT

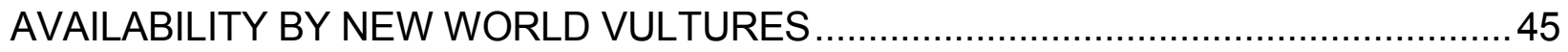

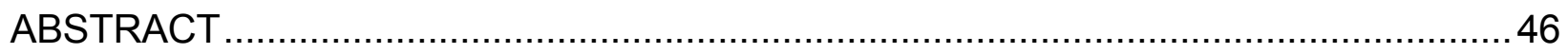

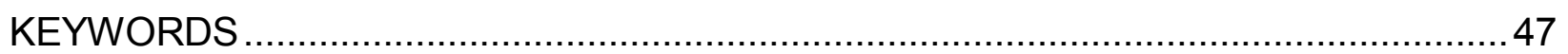

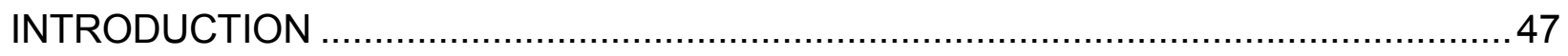

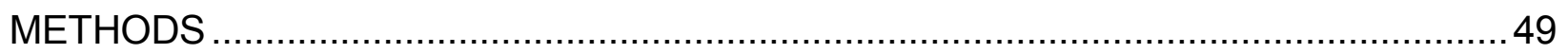

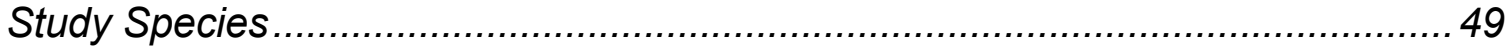

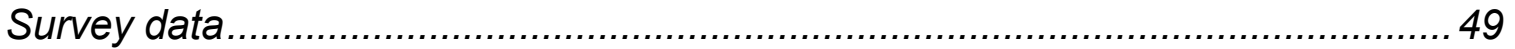

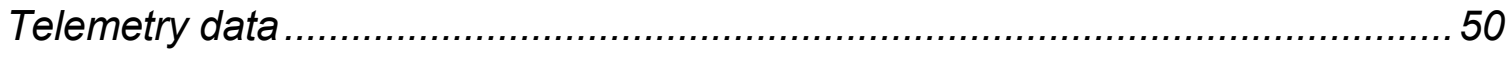

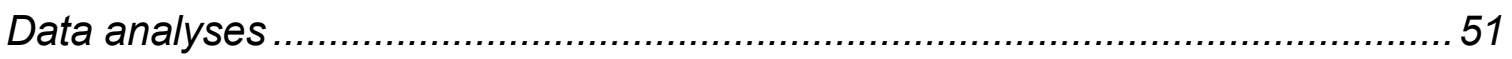

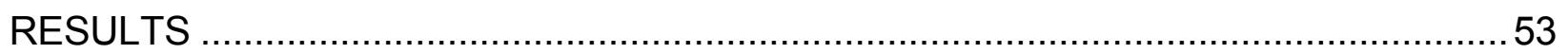

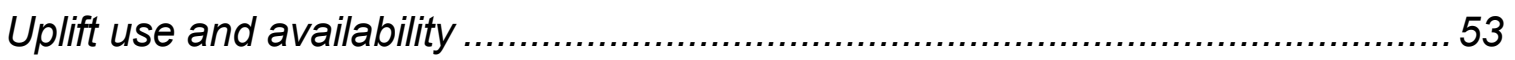

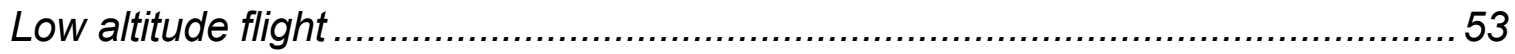

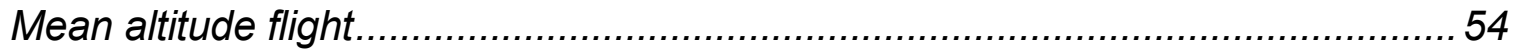

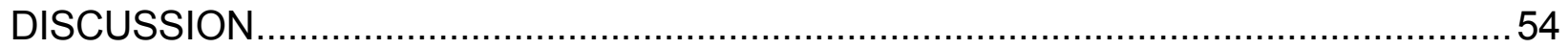

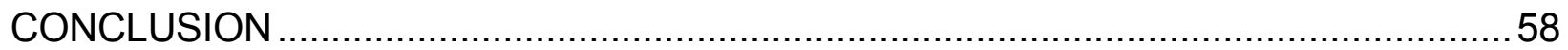

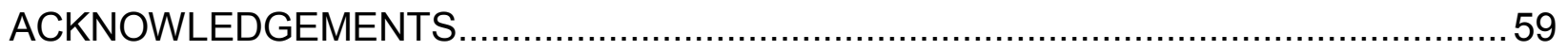

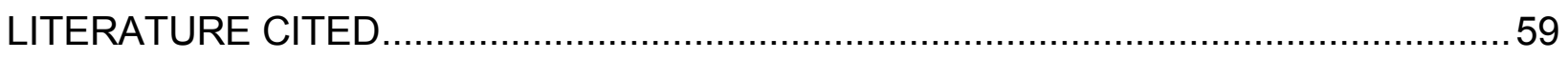

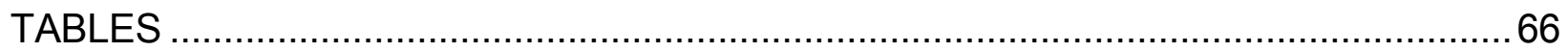


FIGURES 


\section{LIST OF FIGURES}

Fig.1-1. Map of site locations in and around Charles City County, Virginia. Imagery shown is provided by National Agriculture Imagery Program (NAIP) from 2010.

Fig. 1-2. Proportion of time using flight types differed by species (see legend). Significance of species differences in mean proportion used indicated: (.) $<0.1$, $\left({ }^{*}\right)<0.05,\left({ }^{* *}\right)<0.01,\left(^{* * *}\right)<0.001$. Black vultures used more thermal soaring than turkey vultures and turkey vultures used more turbulent and linear soaring than black vultures. Flapping flight is not included as we did not observe sustained flapping flight by either species.

Fig. 1-3. Proportion of time spent in each altitudinal range by species. Altitudinal ranges are: $<10,11-25,26-50,51-100$, and 101-200 m. Turkey vultures spent more time at lower altitudes than black vultures (Wilcox Rank Test: W $=56718.5, \mathrm{p}-$ value $<0.0001)$.

Fig. 1-4. Mean log-transformed altitudes by flight type and species. Altitudes are above ground level (AGL). Significance of species differences in mean altitudes indicated: $()<0.1,.\left({ }^{*}\right)<0.05,\left({ }^{* *}\right)<0.01,\left({ }^{* * *}\right)<0.001$. There was no difference in mean flight altitudes of species using turbulent soaring and marginal difference in mean flight altitudes of species using linear soaring. Black vultures flew significantly higher than turkey vultures when using thermal soaring or gliding. Flapping flight is not included as we did not observe sustained flapping flight by either species. 
Fig. 1-5. Species use versus estimated background availability of $(A)$ turbulent uplift (TKE; $\mathrm{J} / \mathrm{kg}$ ) and $(B)$ thermal uplift $(\mathrm{m} / \mathrm{s})$. Uplift availabilities estimated from NARR data provided by NCEP and accessed via Movebank's Env-data. Background uplift availability (solid) compared to black vulture (dashed) uplift use and turkey vulture (dotted) uplift use.

Fig. 1-6. The strengths of modeled TKE $(\mathrm{J} / \mathrm{kg})$ and thermal $(\mathrm{m} / \mathrm{s})$ uplift intensities available during observation periods. TKE and thermal uplift were correlated $(r=0.6778)$, and therefore are often strong at the same time.

Fig. 1-7. Proportionate use of turbulent and thermal soaring by vultures in response to edge length at sites. Vultures generally increased use of turbulent soaring with forest edge length, but the trend is non-significant $(b=1.981-05, t(13)=1.410$, $p<0.27)$. Neither species varied use of thermal soaring by forest edge length $(b=-3.82 e-06, t(13)=-0.354, p=0.73)$.

Fig. 2-1. Map of eight regions surveyed (letters) across the Americas and telemetered bird breeding (open-circle) and non-breeding (closed-circle) locations. Breeding and non-breeding locations did not have to overlap with regions surveyed, but were included if geographically similar.

Fig. 2-2. Distribution of thermal uplift $(\mathrm{m} / \mathrm{s})$ in regions surveyed for vultures across the Americas. Regions are organized from highest to lowest in absolute latitude. Because some populations were obligate migrants, Canada, Southern South America, and Central US regions had no data during the non-breeding season. The dashed line indicates the mean uplift intensity. Thermal uplift is positively 
associated with absolute latitude during the breeding season and negatively associated with absolute latitude during the non-breeding surveyed.

Fig. 2-3. Distribution of TKE $(\mathrm{J} / \mathrm{kg})$ (an indicator of turbulent uplift intensity) in regions surveyed for vultures across the Americas. Regions are organized from highest to lowest in absolute latitude. TKE data was only available for regions between $54 \mathrm{~N}-12 \mathrm{~N}$ and therefore unavailable in certain regions surveyed. The dashed line indicates the mean uplift intensity. Turbulent uplift is negatively associated with absolute latitude during both seasons.

Fig. 2-4. Uplift intensities (TKE and thermal) at road survey locations versus absolute latitude. TKE $(\mathrm{J} / \mathrm{kg})$ intensity decreases with absolute latitude during both seasons. TKE intensity decreased slightly during the non-breeding season. Thermal uplift intensity increased with latitude during breeding seasons (April September in northern hemisphere; November - March in southern hemisphere) but had no trend during non-breeding season.

Fig. 2-5. Mean altitudes of black and turkey vulture flights $<200 \mathrm{~m}$ by absolute latitude. Log-transformed above ground level (AGL) altitudes were summarized by locale. Mean flight altitude increased slightly with latitude during the breeding season for both species. Black vultures low altitude flights did not respond to absolute latitude ( $p$-value $=0.855$ ). Turkey vulture low altitude flights did respond to absolute latitude ( $p$-value $=0.0103$ ).

Fig. 2-6. Proportion of low altitude flights ( $<=50 \mathrm{~m} \mathrm{AGL}$ ) by turkey and black vultures versus mean TKE $(\mathrm{J} / \mathrm{kg})$ for each locale surveyed. Turkey vultures increased 
low altitude flights with increasing TKE intensity ( $p$-value=0.211). Black vulture low altitude flights had no response to TKE intensity ( $p$-value $=0.858)$.

Fig. 2-7. Distribution of flight altitudes of surveyed vultures by region. Regions are organized (top to bottom) furthest from the equator to closest to the equator. Vultures were categorized as $<10,11-20,21-30,31-50,51-100$, or $101-200 \mathrm{~m}$ above ground level (AGL). Black bar indicates median flight altitude. Black vultures (left column) were absent from Canada and Midwest US. Black vultures consistently flew higher than turkey vultures. 


\section{LIST OF TABLES}

Table 1-1. Vulture's hourly proportionate use of uplift type (thermal, turbulent, linear, soaring) as a response to local weather conditions. Final models include only significant interaction terms.

Table 2-1. List of regions and locales surveyed during breeding (BS) and non-breeding (NBS) seasons. Rate of birds encountered varied by latitude and season.

Table 2-2. Summary data of turkey vultures used in telemetry analyses. Breeding or nonbreeding locations and latitudes used in analyses are included. Locations were excluded from analyses if were not geographically similar to regions surveyed. Bird indicated with a * was non-migratory and occupied the same region yearround. The number of days birds were tracked varied among individuals and by date of capture.

Table 2-3. Linear mixed model summary for altitude above ground level (AGL) of telemetered turkey vultures. Turkey vultures $(n=13)$ ranged from lower Canada and eastern USA in the breeding season to Northern South America in the nonbreeding season. Values shown are for the final model. TKE and thermal uplift intensities are provided by North American Regional Reanalysis (NARR). 
CHAPTER 1

\section{IN-FLIGHT TURBULENCE BENEFITS SOARING BIRDS}


Julie M. Mallon ${ }^{1}$

Keith L. Bildstein²

Todd E. Katzner ${ }^{1,3}$

${ }^{1}$ Division of Forestry and Natural Resources, West Virginia University, Morgantown, WV 26506, USA

2 Hawk Mountain Sanctuary, Acopian Center for Learning, 410 Summer Valley Rd., Orwigsburg, PA 17961, USA

${ }^{3}$ United States Geological Survey, Forest and Rangeland Ecosystem Science Center, Boise, ID, USA

\section{ABSTRACT}

Identifying and characterizing uplifts used by soaring birds is necessary to understand their flight behavior. We observed highly variable soaring flight patterns inconsistent with published descriptions of soaring flight. Because turbulence is widely available and could cause variable flight patterns, we hypothesized that some avian species soar using turbulent uplift. We tested our hypothesis by observing flights of black (Coragyps atratus) and turkey vultures (Cathartes aura) to determine if flight patterns were consistent with use of environmental turbulence to gain lift. We observed vulture flights at low altitudes, indicating use of turbulent winds within the boundary layer. Black and turkey vulture flight behavior were consistent with uplift availability. We found that turkey vultures used turbulent uplift more often than did black vultures. Turbulent uplift, which increased duration of flights at low altitudes, may be necessary for turkey vultures 
to detect carrion olfactively. The species differences we observed indicate speciesspecific flight strategies, which may serve to reduce resource competition and promote sympatry.

\section{KEYWORDS}

soaring, flight behavior, uplift, turbulence, black vulture, turkey vulture, boundary layer

\section{INTRODUCTION}

Uplift is an important resource for soaring birds. By soaring instead of flapping, birds can save energy and move with lower metabolic costs (Baudinette and SchmidtNielsen 1974). Soaring species have evolved anatomical adaptations to better use certain uplift types (Rosser and George 1986, Meyers and Stakebake 2005). Soaring flight is limited to periods when weather is favorable for uplift development (Kerlinger et al. 1985; Kerlinger 1989; Spaar 1995; Leshem and Yom-Tov 1996; Liechti et al. 1996, Mellone et al. 2012), and the distributions of soaring species are limited to regions where uplift is sufficient in strength (Houston 1976, 1983, Suryan et al. 2008). Whereas some species are flight generalists (Klaassen et al. 2011), soaring species require external sources of uplift to move regularly (Pennycuick and Scholey 1984).

Birds use various types of environmental uplift to soar. Birds soar using changes in potential and kinetic energy (Pennycuick 2008) to maintain or gain altitude. Pelagic soaring birds use dynamic soaring (Pennycuick 1982), also known as gust soaring (Pennycuick 2002), which is available in marine environments (Weimerskirch et al. 2000). Terrestrial birds soar using orographic or thermal uplift to subsidize flight. Orographic uplift 
(also known as slope uplift) is generated by winds deflected over topographic relief (Pennycuick 1975, Pennycuick and Scholey 1984, Kerlinger 1989). Orographic uplift is spatially restricted in comparison to thermal uplift, which is widely distributed (Pennycuick 1975). Thermals (units of thermal uplift) are vortices of ascending hot air surrounded by descending cooler air (Pennycuick 1975, Oke 1987, Kerlinger 1989), generated by differential heating of the earth's surface.

Several researchers have speculated that turbulence produces uplift useable by soaring birds (Hendriks 1972, Pennycuick 1972, 1975), although it has never been shown empirically. Before our field studies, we occasionally observed birds soaring linearly, but with vertical and horizontal deviations from a straight-line path at low altitudes; this flight pattern was inconsistent with use of the types of uplift described above. Flight patterns consistent with our observations have been described previously for other Cathartid vultures (Houston 1988). Aside from vultures, other species have been observed to use soar in patterns suggesting use of turbulence as uplift, including black kite (Pennycuick 1972), zone-tailed hawk (Mueller 1972), bald eagle, American crow, and red-shoulder hawk (pers. obs.).

We hypothesized that terrestrial soaring birds use uplift generated in the turbulent surface layer, $<50 \mathrm{~m}$ above ground level (AGL) (Oke 2002), to subsidize their flight. We refer to this as the turbulent-soaring hypothesis. Turbulent eddies are irregular or chaotic air flows that occur everywhere on earth (Bagnato et al. 2013). They are generated both convectively by non-uniform thermal conditions and mechanically by air flowing around obstructions in the turbulent surface layer. Turbulent eddies are found on the lee sides of 
such obstructions (e.g. hills, valleys, buildings, etc.), while deflected winds are found on the windward side of these obstructions.

Turbulence is strongest in the boundary layer near the earth's surface and decreases with altitude (Geiger 1961). Therefore, we expected use of turbulent uplift to be restricted to low altitudes where turbulence is strongest. Previous studies of Cathartid vultures suggest extensive use and preference for thermal soaring (Pennycuick 1983, Bohrer et al. 2011). Hence, we expected vultures to select thermal uplift over turbulent uplift. However, we also expected turbulent soaring to be used more when weather conditions are poor for thermal formation. Due to differences in anatomy, especially the turkey vultures' (Cathartes aura) dihedral wing profile and long tail, we expected turkey vultures to use turbulent uplift relatively more frequently than black vultures (Coragyps atratus).

To test our turbulent-soaring hypothesis, we observed flights of black and turkey vultures in coastal Virginia, United States. Many recent studies rely on use of remote sensing to describe movement and bird flight (DeVault et al. 2005, Katzner et al. 2012, Klaassen et al. 2012, Sapir et al. 2011, Suryan et al. 2008). Turbulence is instantaneous due to its diffusivity and, therefore, difficult and expensive to measure remotely (Bagnato et al. 2013.). Instead, we used direct observations of soaring birds and made inferences based on observed flight patterns, a method many researchers have used to classify flight behavior previously (Huffaker 1897, Idrac 1924, Cone 1962, Pennycuick 1972, McGahan 1973, Bildstein 2009). 
Our research had the following objectives. First, we evaluated mean flight altitudes for each species and by flight type to determine if use of flight types were restricted to certain altitudes. Second, we evaluated variation in proportional use of flight types as they related to local weather variables to understand the conditions under which vultures used each flight type. Third, we compared uplift use to background availability to determine if vultures select for certain uplift types or strengths. Fourth, we compared use of each type of uplift among land cover types and sites to determine how variation in the terrestrial environment affected uplift use. We conclude by discussing the ecological implications of the use of turbulent uplift by soaring birds.

\section{METHODS}

We chose to observe vultures because they forage on the wing and are dependent on soaring flight. We selected southeastern Virginia, USA as our study region because vultures were locally abundant and there was little topographic relief, simplifying our observations by removing the possibility of vultures using orographic uplift.

We collected data on the flight behavior of vultures by observing flights at 13 sites that represented three locally common land-cover types: agricultural fields $(n=5)$, rivers $(n=4)$, and roads $(n=4)$. Fig. 1-1 shows locations of sites by land cover type. Field sites varied in composition: corn $(n=2)$, wheat $(n=2)$, fallowed/mixed $(n=1)$. River sites varied in width at the narrowest point from $0.25 \mathrm{~km}-1.13 \mathrm{~km}$. Road sites were all 4-lane highways in commercial areas with cleared adjacent lots. Our sites were chosen by land-cover type, but varied in area and amount of forest edge.

At each site, we measured behavior during two-hour observation bouts between $900-1700 \mathrm{~h}$; this time of day corresponds to maximum foraging activity of vultures (Kirk 
and Currall 1994). Two observers used binoculars and a spotting scope to observe flights of focal subjects. We chose our focal birds randomly by selecting the next bird that entered the site. To remove sampling bias of very low flights and vultures leaving the study site, we only analyzed flights that were at least $30 \mathrm{~s}$ long. To characterize vulture flight, we recorded the duration of each focal subject's behavior (i.e. flight type and altitude) until the focal subject left the site. We suspended observation if view of a focal bird was obstructed and resumed observation when the focal bird reentered our field of view.

\section{Study species}

Black and turkey vultures are among the smallest species of vultures globally. Both are lightly wing loaded: Houston (1988) estimated wing loadings of 40.6 and $57.6 \mathrm{~N} / \mathrm{m}^{2}$ for turkey and black vultures, respectively. Black vultures have short, wide wings and a short, fan-shaped tail, which enables them to rise quickly in thermals. In contrast, turkey vultures have longer, narrower wings that are held in a dihedral, and a long, rounded tail that they rarely flare but use to aid mobility. Their dihedral wing posture acts to stabilize and stay upright in turbulent winds (Mueller 1972, Pennycuick 1975).

Flight type use

We characterized flight into five types: flapping, gliding, linear soaring, thermal soaring, or turbulent soaring. We recognized flight types in the field using the following guidelines:

- Flapping: sustained powered flight (>5 s of continuous flapping)

- Gliding: slightly tucked wings in straight-line flight with loss of altitude

- Linear: soaring in a straight line with no loss of altitude 
- Thermal: circular soaring while gaining altitude

- Turbulent: soaring with observable deviations, either vertically, horizontally (e.g. a rocking motion), from a straight-line path

We calculated species' proportionate use of each flight type for each hour of observation. We then tested for species differences in proportionate use of each flight type, and for species differences in flight altitudes for each flight type using rank sum tests.

Altitude

Because accuracy of estimates declined with increasing altitude, we classified flight behavior into the following altitude classes for analysis: $<10,11-25,26-50,51-100$, and 101-200 m above ground level (AGL). By using altitude classes, we were able to accurately record the time vultures spent at different heights. We used the maximum altitude within the range for our calculations to correct for under-estimating altitudes from the ground. For analysis, we summarized species' mean log-transformed flight altitudes for each hour of observation. We tested for species differences in flight altitudes using rank sum tests.

We verified that our altitude estimates were reasonable by measuring the flight altitudes of two black vultures and 1 turkey vulture over one year with GPS telemetery. Birds were caught using cannon nets in Virginia from August through October 2013. Vultures were equipped with $50 \mathrm{~g} \mathrm{CTT-1050} \mathrm{(Cell} \mathrm{Track} \mathrm{Tech,} \mathrm{Somerset,} \mathrm{PA)} \mathrm{telemetry}$ units that collected location and altitude data at $15 \mathrm{~min}$ intervals. Collected data were transmitted daily by Global System for Mobile Communications (GSM) network. We calculated altitudes AGL by subtracting local elevation from altitudes above sea level 
(ASL). We analyzed the altitudes >-50 m AGL (Katzner et al. 2012) recorded from $900-$ $1700 \mathrm{~h}$ and with high quality fixes (hdop <10) (Lanzone et al. 2012).

To test whether vultures flew at flight altitudes specific to each flight type, we used two-way analysis of variance (ANOVA) across sites $(n=13)$ for each species. We evaluated significance of the difference of altitude for each flight type combination using Tukey's honestly significant difference method. We used Bonferroni's adjustment to account for the use of multiple ANOVAs.

\section{Uplift selection}

To determine if vultures selected thermal or turbulent uplifts at certain strengths, we compared uplift intensities used by vultures to background uplift intensities. We used turbulent kinetic energy (TKE) to estimate turbulence intensity near the earth's surface. Thermal uplift $\left(\mathrm{ms}^{-1}\right)$ was provided by Movebank Env-Data and TKE $\left(\mathrm{Jkg}^{-1}\right)$ was provided by North American Regional Reanalysis (NARR) (NOAA's National Center for Atmospheric Prediction (NCEP)) data available via Movebank Env-Data (Dodge et al. 2013). We used data available via Movebank for "used" and "background" uplift intensities. We used surface pressure $(1000 \mathrm{mb})$ thermal and TKE intensities at $15 \mathrm{~min}$ intervals during observations as "background" uplift availability. Instances during observed flights when vultures used thermal or turbulent soaring determined "used" uplift.

We used generalized linear mixed models to evaluate effects of local weather conditions on use of each flight type. Our response variable was species' proportionate use of each flight type. As fixed effects, we used gust speed, temperature, and humidity, as measured at the weather station nearest to each site (Weather Underground, www.wunderground.com). We also included hour and cloud cover as fixed effects, which 
we recorded in our field notes at 15-minute intervals during observations. We described cloud cover as clear ( $<20 \%$ clouds), partly cloudy $(20-80 \%$ clouds), and overcast $(>80 \%$ clouds). We used site as a random effect to account for repeated measures. Models were selected stepwise by dropping the least informative interaction term (Bolker et al. 2008). All first-order terms were kept, regardless of importance to the model for comparison across flight types and species.

\section{Landscape}

We binned flight type by cover class and calculated proportion of time birds spent in each flight type over each land cover type. To assess uplift use across the landscape, we compared uplift use by primary land cover type and by amount of forest edge. We measured forest edge at 1:5,000 scale using from National Agriculture Aerial Imagery (NAIP) 2010 with a 1-m resolution and a Lambert Coniformal Conic projection. We used linear models to evaluate the effect of forest edge on flight type use. We used a KruskalWallis test to determine if the flight types vultures used varied in response to primary land cover.

\section{RESULTS}

We recorded 107 black vulture flights and 464 turkey vulture flights during 1612 hour periods of observation in May - July 2013 and June 2014. Observed flights lasted $254 \pm 189 \mathrm{~s}$ for black vultures and $235 \pm 229 \mathrm{~s}$ for turkey vultures. We observed for 108 hours during the morning $(900-1130), 108$ hours during early afternoon (1130-1430), and 106 hours during late afternoon (1430 - 1700). Sunny conditions prevailed during 100 hours, partly cloudy conditions for 104 hours, and overcast conditions during 118 hours of observation. 


\section{Influence of flight type on altitude}

We did not observe vultures using sustained flapping flight. Instead, we noted when vultures flapped intermittently while using other flight types. Turkey vultures flapped at least once during $47 \%$ of flights while black vultures flapped at least once during $66 \%$ of flights. Both species flapped most at $<50 \mathrm{~m}$ AGL. Black vultures were most likely to flap whilst thermalling, while turkey vultures were equally likely to flap using thermal or turbulent soaring.

Vultures almost always used multiple flight types. Black vultures used multiple flight types in $84 \%$ of flights and turkey vultures used multiple flight types in $83 \%$ of flights. Although thermal soaring was almost always followed by gliding, gliding flight sometimes occurred without thermal soaring. Grouping thermal soaring and gliding together, black vultures used multiple flight types in $56 \%$ of flights and turkey vultures used multiple flight types in $75 \%$ of flights. Black vultures used thermal soaring in $85 \%$ of their flights, turbulent soaring in $35 \%$ of flights, linear soaring in $36 \%$ of flights, and gliding in $73 \%$ of flights. Turkey vultures used thermal soaring in $66 \%$ of flights, turbulent soaring in $67 \%$ of flights, linear soaring in $53 \%$ of flights, and gliding in $70 \%$ of flights.

Black vultures used thermal soaring and gliding more than did turkey vultures (Fig 1-2). Black vultures thermalled $51 \%$ of the time whereas turkey vultures thermalled $32 \%$ of the time $(U=13, Z=3.67, p<0.001)$. Black vultures used gliding $30 \%$ of the time and turkey vultures used gliding $22 \%$ of the time $(U=13, Z=1.97, p<0.05)$. Turkey vultures used turbulent and linear soaring more than did black vultures (Fig. 1-2). Turkey vultures used linear soaring $17 \%$ of the time, whereas black vultures used linear soaring $9 \%$ of the 
time $(U=13, Z=-2.48, p<0.05)$. Turkey vultures used turbulent uplift $29 \%$ of the time, whereas black vultures used turbulent soaring $10 \%$ of the time $(U=13, Z=-3.41, p<0.001)$.

Overall, turkey vultures $(\bar{x}=38.0 \mathrm{~m} \mathrm{AGL}, 95 \% \mathrm{Cl}=22.4-64.3)$ flew lower than black vultures $(\bar{x}=55.4 \mathrm{~m}, 95 \% \mathrm{Cl}=29.8-103.0 ; \mathrm{U}=13, \mathrm{~W}=3409, \mathrm{p}$-value $<0.0001$; Fig. 1-3). Analysis of variance (ANOVA) indicated that turkey vulture flight altitude was usually dependent on the type of flight they were engaged in $(F 3,9=124.7 p$-value $<0.0001$ ); only thermal and gliding ( $p$-value $>0.05$ ) flights were at similar altitudes. Exactly the same pattern was evident for black vultures $(F 3,9=25.46$, $p$-value $<0.0001)$. Mean flight altitude during soaring and gliding differed among species (Fig 1-4). When using thermal soaring, black vultures flew at $62 \mathrm{~m} \mathrm{AGL}$ and turkey vultures flew at $44 \mathrm{~m} \mathrm{AGL}$ $(U=13, Z=3.05, p<0.005)$. When gliding, black vultures flew at $63 \mathrm{~m} \mathrm{AGL}$ and turkey vultures flew at $44 \mathrm{~m}$ AGL $(U=13, Z=3.257, p<0.005)$. When engaged in linear soaring, black vultures flew at $46 \mathrm{~m} \mathrm{AGL}$ and turkey vultures flew at $37 \mathrm{~m} \mathrm{AGL}(U=13, Z=1.62$, $p=0.1)$. When using turbulent soaring, black vultures flew at $31 \mathrm{~m} \mathrm{AGL}$ and turkey vultures flew at $29 \mathrm{~m} \mathrm{AGL}(U=13, \mathrm{Z}=-0.18, p=0.85)$ Fig. 1-4). Turbulent soaring was near-exclusively $<50$ m AGL (>99\% of observations).

Mean altitudes of telemetered birds were similar to mean altitudes of birds recorded by observation. Our sparse telemetry data suggest that both species, when flying $<200 \mathrm{~m}$, flew at mean altitudes less than $50 \mathrm{~m}$ AGL and the turkey vulture $(\mathrm{n}=1, \bar{x}=$ $13 \pm 45)$ flew lower than the two black vultures $(n=2, \bar{x}=45 \pm 68)$. Actual mean flight altitudes were expectedly higher for the turkey vulture $(n=1, \bar{x}=128 \pm 293)$ and black vultures $(n=2, \bar{x}=130 \pm 184)$. 


\section{Weather conditions influence flight type use}

Mixed model analysis suggested that use of thermal uplift was generally influenced by meteorological variables associated with solar radiation (Table 1-1). Turkey vultures used thermal soaring most during sunny conditions, and increased use of thermal soaring with temperature during overcast and partly cloudy conditions. Black vultures used thermal soaring most during sunny conditions and increased with wind speed, but decreased thermal soaring when humidity and temperature were above average.

Vultures used gliding and linear soaring under conditions similar to those in which they used thermal soaring. Linear soaring by turkey vultures was less frequent at above average winds and was more frequent at above average temperatures. Linear soaring by black vultures was less frequent at above average temperatures when humidity was above average, but was more frequent with above average temperature during partly cloudy conditions. For both species, gliding flight decreased with humidity and hour, but increased with temperature. Black vultures used gliding less with above average temperatures during partly cloudy conditions.

Both species used turbulent uplift most during conditions that were not favorable for thermal development. Turbulent uplift use by both species increased at above average humidities but decreased use at above average temperatures. Black vultures decreased their use of turbulent soaring when both wind speed and temperature were above average but increased use of turbulent soaring with hour.

\section{Uplift selection}

Black vultures selected thermal uplift over turbulent uplift. Turkey vultures used thermal uplift as it was available (Fig. 1-5b). Both species used turbulent soaring when 
TKE values were low (Fig. 1-5a). Thermal uplift in the environment was correlated with TKE in the environment ( $r=0.6778$, Fig. 1-6). Influence of landscape variables on uplift use

Vultures appeared to increase the frequency with which they engaged in turbulent soaring as the amount of forest edge increased at a site (Fig. 1-7) but the trend was not statistically significant $(b=1.981-05, t(13)=1.410, p=0.27)$. Neither species varied use of thermal soaring by forest edge length $(b=-3.82 e-06, t(13)=-0.354, p=0.73)$.

Neither turkey vultures $\left(X^{2}=5.0969, \mathrm{df}=2, \mathrm{p}\right.$-value $\left.=0.0782\right)$ nor black vultures $\left(X^{2}=3.2907, d f=2, p\right.$-value $\left.=0.1929\right)$ varied flight altitude among habitat types. There were, however, differences in proportions of flight types used by turkey vultures among habitat types. Turkey vultures used turbulent soaring most at river habitats and least at open field sites $\left(X^{2}=10.2607, d f=2, p\right.$-value $\left.=0.005914\right)$. Conversely, turkey vultures used linear soaring more often at open fields and less often at river sites $\left(X^{2}=6.4849, \mathrm{df}=\right.$ 2 , $p$-value $=0.03907)$. Turkey vultures did not vary the amount of thermal soaring $\left(X^{2}=\right.$ $3.8157, \mathrm{df}=2, \mathrm{p}$-value $=0.1484)$ or gliding flight by habitat type $\left(\mathrm{X}^{2}=2.5074, \mathrm{df}=2, \mathrm{p}\right.$ value $=0.2854)$. Black vultures did not vary flight type used among habitat types.

\section{DISCUSSION}

\section{Turbulent soaring}

In spite of previous work suggesting that North American vultures predominantly use thermal uplift (Pennycuick and Scholey 1984, DeVault et al. 2005, Mandel et al. 2008, 2011, Bohrer et al. 2011), our results indicate Cathartid vultures spend a great deal of their time soaring using turbulent uplift (Fig 1-2). Not surprisingly, use of turbulent uplift by both species was restricted to low altitudes (Fig. 1-4) where turbulence is greatest 
(Geiger 1961). Furthermore, both species used each uplift type during similar weather conditions (Table 1-1) in response to relative availability of thermal and turbulent uplift. Flight patterns of both species were consistent with the availability of turbulence, supporting our hypothesis that both are indeed using uplift generated in the turbulent surface layer near the earth's surface.

Turbulent soaring, like turbulence, is difficult to describe but easy to recognize in the field. The variability of turbulent soaring flight paths is easily recognized in contrast to more linear flights (such as gliding or linear soaring) and circular thermalling. Turkey vultures always held their wings in a dihedral and often would rock side-to-side while flying linearly. While black vultures normally hold their wings flat, we occasionally observed black vultures to also rock while holding a slight dihedral when using turbulent soaring. During these flights, the focal bird would have irregular vertical or horizontal movements that were distinct from the straight-line flights of linear soaring or gliding. In these instances, vultures appeared to use turbulent eddies and deflected winds for uplift. These flight patterns mimicked small-scale orographic soaring. Furthermore, we observed unsteady linear flight and high banking flight patterns often together by the same focal bird. We decided to call this "turbulent soaring" because these flight patterns are clearly associated with turbulence.

Although most turbulent soaring flights were linear, a small proportion of the flights we categorized as "turbulent soaring" involved tortuous movements and high-banking patterns, where vultures used wind shear for uplift. During gusts, birds appeared to turn perpendicular to the wind and were swept sideways. Some of these flights may also be 
considered similar to gust soaring in a terrestrial environment. Pennycuick (1972) observed this in black kites (Milvus migrans), and Houston (1988) observed the same flight pattern in all three Cathartes species. Additional description of flight patterns similar to turbulent soaring may be found elsewhere (Stager 1964, Arrington 2003). Uplift use

TKE at high altitudes has previously been used to estimate thermal uplift within the boundary layer (Mandel et al. 2008, Sapir et al. 2011). We used surface level TKE, which approximates atmospheric turbulence intensity. TKE, which has been used to estimate thermal uplift at higher altitudes (Sapir et al. 2011), was correlated with thermal uplift intensity (Fig. 1-6). This suggests the modeled TKE values are driven by convective turbulence. Both species used turbulent soaring most when TKE was very low (Fig. 1-5a), suggesting vultures are using mechanical turbulence generated near obstructions to soar. Furthermore, high-resolution meteorological models such as NARR are spatially and temporally coarser than the behavioral data we collected. Poor prediction of turbulent uplift use by vultures, therefore, is likely due to the inability of meteorological models to resolve small-scale mechanical turbulence.

Uplift use by turkey vultures varied among landcover types, further suggesting turbulent uplift strength is driven by small-scale factors. Turkey vultures used turbulent soaring most at river sites, where thermal uplift is less likely to develop (Richardson 1978) and wind speeds are greater (He et al. 2010). Turkey vultures used turbulent soaring less at open fields in areas where thermal uplift was more likely. Our results suggest use of low altitude turbulent and linear soaring is more influenced by land cover than higheraltitude thermal soaring and gliding. 
Turbulent uplift is more likely to be useable by soaring birds in forested landscapes than open-habitat areas where there is less predictable mechanical turbulence. Birds have previously been observed soaring using deflected winds over trees (Huffaker 1897, Cone 1962, Kerlinger and Gauthreaux 1985). The strength of vertically deflected winds is a fraction of the horizontal wind speed (Irvine et al. 1997), but appears to be sufficiently strong for soaring flight of lightly wing-loaded birds. These observations support our observation that turbulent soaring generally increased with forest edge length at sites (Fig. 1-7).

Although uplift use was site-specific and related to landcover type, black and turkey vultures used each flight type during similar weather conditions across all sites (Table 1-1). Both species decreased use of turbulent soaring while increasing use of thermal soaring during conditions that are optimal for thermal development (Bradbury 2004). Black and turkey vultures, therefore, exhibited patterns consistent with optimization of their flight strategies by increasing use of uplift during favorable weather conditions.

Turkey vultures used thermal uplift in direct proportion to its availability but used turbulent soaring more often at low TKE intensities (Fig. 1-5). The lack of thermal uplift selection by turkey vultures suggests they are opportunistic, generalist flyers and use uplift as it is available. Furthermore, turkey vultures near exclusively used multiple flight types in sequence, which may be because turbulent and thermal uplifts were often available at the same time (Fig. 1-6). Black vultures, although also used multiple flight types in sequence, primarily selected strong thermals to soar in (Fig. 1-5) suggesting they 
are thermal soaring specialists. Black vultures may have been less active overall compared to turkey vultures due to their selection of strong thermal uplift.

Species-specific flight patterns

Under the same environmental conditions, the flight behavior of black and turkey vultures differed. Turkey vultures used thermal soaring and turbulent soaring equally, whereas black vultures used thermal soaring four-times as often as they used turbulent soaring (Fig. 1-2). Moreover, turkey vultures flew lower than black vultures when using thermal uplift (Fig. 1-4), indicating these species use this resource differently. These differences in flight altitude and rates of flight type use indicate flight strategies are species-specific.

Because vultures search for food on the wing, differences in flight behavior may have evolved with diverging foraging strategies and resource use, ultimately affecting their ecological roles as scavengers. By using thermal uplift more often (Fig. 1-2) and foraging at higher altitudes than turkey vultures (Fig. 1-3; Houston 1988, Buckley 1996), black vultures may select a subset of available carrion resources best suited to detection with this foraging strategy. Black vultures forage in groups (Rabenold 1987) and rely on social facilitation (Buckley 1996, Rabenold 1987, Jackson et al. 2008, Mallon et al. 2013) to find carcasses more so than do turkey vultures. In addition, black vultures are more likely to select large food sources (Stewart 1978, Coleman and Frazer 1987, Ruxton and Houston 2004) that can be used by multiple scavengers and are easy to detect at higher altitudes. Black vultures also forage in more open land cover types (Lemon 1991, DeVault et al. 2004) where carcasses are easier to detect visually. 
Although both species detect carcasses visually (Lisney et al. 2013), turkey vultures also use smell to locate carrion (Bang 1960), allowing them to detect carcasses concealed by forested land cover. Olfactive foraging is likely to be more successful at low flight altitudes (Stager 1964) because the olfactive gradient at higher altitudes is too dispersed to facilitate detection of carrion (Smith and Paselk 1986). By flying at lower altitudes (Fig. 1-3), turkey vultures use more small or concealed carrion resources (Stewart 1978, Coleman and Frazer 1987) than black vultures.

When sympatric, black vultures often parasitize turkey vultures by following them to carrion. Groups of black vultures will displace turkey vultures at carcasses (Stewart 1978, Houston 1988). But by discovering a carcass (Houston 1988), turkey vultures have the "finders share" of a carcass, or the opportunity to consume a smaller carcass before competitors arrive. Hence, species differences in flight behavior may reduce resource competition and promote sympatry (Kirk and Gosler 1994).

\section{CONCLUSION}

Because uplift use differed between two species in the same family, use of turbulent uplift is likely restricted to species with similar behavior or anatomy. Other species that may use turbulent soaring should (1) search for food on the wing (such as harriers), or (2) have similar anatomical features such as light wing loading or a dihedral wing posture (such as zone-tailed hawks). We suspect a dihedral wing posture is the most essential feature as it helps turkey vultures maintain uprightedness in turbulent winds (Mueller 1972) and improves agility without losing speed or height, but at a cost of increased uplift intensity requirements. We expect that many soaring species are able to use turbulent uplift under certain conditions (such as high wind speeds). We observed 
frequent use of turbulent soaring by vultures, which calls for more observational studies of other soaring species to determine if they also use turbulence to soar. Future studies on the movements, distributions, and resource selection by soaring species should consider the potential use of all uplift types, including turbulent uplift.

\section{ACKNOWLEDGEMENTS}

We acknowledge Hawk Mountain Sanctuary and the Burket-Plack Foundation provided funding for this project. Kirstin Fagan and Payton Philips assisted in data collection. Jeff Cooper and Eric Frank trapped and deployed telemetry units on black and turkey vultures in Virginia. Virginia DGIF and New Kent Forestry Center provided housing during our field seasons.

\section{LITERATURE CITED}

Arrington, D.P. (2003) Flight characteristics of non-migrating and migrating populations of turkey vultures. Purdue University, Lafayette, Indiana.

Bagnato, V.S., Shiozaki, R.F., Seman, J.A., Henn, E. a. L., Telles, G., Tavares, P., Roati, G., Bagnato, G., Magalhães, K.M.F., Muniz, S.R. \& Caracanhas, M. (2013) Characteristics and perspectives of quantum turbulence in atomic bose-einstein condensates. Physics of Quantum Fluids Springer Series in Solid-State Sciences. (ed. by A. Bramati and M. Modugno), pp. 301-314. Springer Berlin Heidelberg.

Bang, B.G. (1960) Anatomical evidence for olfactory function in some species of birds. Nature, 188, 547-549.

Baudinette, R.V. \& Schmidt-Nielsen, K. (1974) Energy cost of gliding flight in herring gulls. Nature, 248, 83-84.

Bildstein, K.L., Bechard, M.J., Farmer, C. \& Newcomb, L. (2009) Narrow sea crossings present major obstacles to migrating griffon vultures Gyps fulvus. Ibis, 151, 382391. 
Bohrer, G., Brandes, D., Mandel, J.T., Bildstein, K.L., Miller, T.A., Lanzone, M., Katzner, T., Maisonneuve, C. \& Tremblay, J.A. (2012) Estimating updraft velocity components over large spatial scales: contrasting migration strategies of golden eagles and turkey vultures: Contrasting migration strategies of two raptors. Ecology Letters, 15, 96-103.

Bradbury, T. (2004) Meteorology and Flight: A Pilot's Guide to Weather, A \& C Black.

Buckley, N.J. (1996) Food finding and the influence of information, local enhancement, and communal roosting on foraging success of North American vultures. The Auk, 113, 473-488.

Coleman, J.S. \& Fraser, J.D. (1987) Food habits of black and turkey vultures in Pennsylvania and Maryland. The Journal of Wildlife Management, 51, 733.

Cone, C.D. (1962) Thermal soaring of birds. American Scientist, 180-209.

DeVault, T.L., Reinhart, B.D., Brisbin, I.L. \& Rhodes, O.E. (2005) Flight behavior of black and turkey vultures: implications for reducing bird-aircraft collisions. Journal of Wildlife Management, 69, 601-608.

DeVault, T.L., Reinhart, B.D., Brisbin Jr, I.L. \& Rhodes Jr, O.E. (2004) Home ranges of sympatric black and turkey vultures in South Carolina. The Condor, 106, 706711.

Dodge, S., Bohrer, G., Weinzierl, R., Davidson, S.C., Kays, R., Douglas, D., Cruz, S., Han, J., Brandes, D. \& Wikelski, M. (2013) The environmental-data automated track annotation (Env-DATA) system: linking animal tracks with environmental data. Movement Ecology, 1, 3.

Geiger, R. (1961) The climate near the ground, revised edition, Harvard University Press, Cambridge.

Hendriks, F. (1972) Dynamic Soaring. PhD Thesis, University of California, Los Angeles.

He, Y., Monahan, A.H., Jones, C.G., Dai, A., Biner, S., Caya, D. \& Winger, K. (2010) Probability distributions of land surface wind speeds over North America. Journal of Geophysical Research, 115.

Houston, D.C. (1976) Breeding of the white-backed and Rüppell's griffon vultures, Gyps africanus and G. rueppellii. Ibis, 118, 14-40.

Houston, D.C. (1988) Competition for food between Neotropical vultures in a forest. Ibis, $130,402-417$. 
Houston, D.C. (1983) The adaptive radiation of the griffon vultures. Vulture Biology and Management, California University Press, Los Angeles.

Huffaker, E.C. (1897) On soaring flight. Annual report of the Board of Regents, Smithsonian Institution, Washington, D.C.

Idrac, P. (1924) Experimental study of the "soaring" of albatrosses. Nature, 115, 532.

Irvine, M.R., Gardiner, B.A. \& Hill, M.K. (1997) The evolution of turbulence across a forest edge. Boundary-Layer Meteorology, 84, 467-496.

Jackson, A., Ruxton, G. \& Houston, D. (2008) The effect of social facilitation on foraging success in vultures: a modeling study.pdf. Biology Letters, 4, 311-313.

Katzner, T.E., Brandes, D., Miller, T., Lanzone, M., Maisonneuve, C., Tremblay, J.A., Mulvihill, R. \& Merovich, G.T. (2012) Topography drives migratory flight altitude of golden eagles: implications for on-shore wind energy development. Journal of Applied Ecology, 49, 1178-1186.

Kerlinger, P. (1989) Flight Strategies of Migrating Hawks, University of Chicago, Chicago, Illinois.

Kerlinger, P. \& Gauthreaux, S.A. (1985) Flight behavior of raptors during spring migration in south Texas studied with radar and visual observations. Journal of Field Ornithology, 394-402.

Kirk, D.A. \& Currall, J.E.P. (1994) Habitat associations of migrant and resident vultures in central Venezuela. Journal of Avian Biology, 25, 327-337.

Kirk, D. \& Gosler, A. (1994) Body condition varies with migration and competition in migrant and resident south American vultures. The Auk, 111, 933-944.

Klaassen, R.H.G., Ens, B.J., Shamoun-Baranes, J., Exo, K.M. \& Bairlein, F. (2012) Migration strategy of a flight generalist, the Lesser Black-backed Gull Larus fuscus. Behavioral Ecology, 23, 58-68.

Lemon, W.C. (1991) Foraging behavior of a guild of Neotropical vultures. The Wilson Bulletin, 698-702.

Leshem, Y. \& Yom-Tov, Y. (1996) The use of thermals by soaring migrants. Ibis, 138, $667-674$.

Lisney, T.J., Stecyk, K., Kolominsky, J., Graves, G.R., Wylie, D.R. \& Iwaniuk, A.N. (2013) Comparison of eye morphology and retinal topography in two species of new world vultures (Aves: Cathartidae): Vision in Cathartid Vultures. The Anatomical Record, 296, 1954-1970. 
Mallon, J.M., Swing, K. \& Mosquera, D. (2013) Neotropical vulture scavenging succession at a capybara carcass in eastern Ecuador. Ornitologia Neotropical, 24, 475-480.

Mandel, J.T., Bildstein, K.L., Bohrer, G. \& Winkler, D.W. (2008) Movement ecology of migration in turkey vultures. Proceedings of the National Academy of Sciences, 105, 19102-19107.

Mandel, J.T., Bohrer, G., Winkler, D.W., Barber, D.R., Houston, C.S. \& Bildstein, K.L. (2011) Migration path annotation: cross-continental study of migration-flight response to environmental conditions. Ecological Applications, 21, 2258-2268.

McGahan, J. (1973) Gliding flight of the Andean condor in nature. Journal of Experimental Biology, 58, 225-237.

Mellone, U., Klaassen, R.H., García-Ripollés, C., Limiñana, R., López-López, P., Pavón, D., Strandberg, R., Urios, V., Vardakis, M. \& Alerstam, T. (2012) Interspecific comparison of the performance of soaring migrants in relation to morphology, meteorological conditions and migration strategies. PLoS one, 7, e39833.

Meyers, R.A. \& Stakebake, E.F. (2005) Anatomy and histochemistry of spread-wing posture in birds. 3. Immunohistochemistry of flight muscles and the "shoulder lock" in albatrosses. Journal of Morphology, 263, 12-29.

Mueller, H.C. (1972) Zone-tailed hawk and turkey vulture: mimicry or aerodynamics? The Condor, 74, 221-222.

Oke, T.R. (2002) Boundary Layer Climates, Routledge.

Pennycuick, C.J. (2002) Gust soaring as a basis for the flight of petrels and albatrosses (Procellariiformes). Avian Science, 2, 1-12.

Pennycuick, C.J. (1975) Mechanics of flight. Avian Biology (ed. by D.S. Farner and J.R. King.), pp. 1-75. Academic Press, New York.

Pennycuick, C.J. (2008) Modelling the Flying Bird, Elsevier.

Pennycuick, C.J. (1972) Soaring behavior and performance of some east African birds observed from a motor glider. Ibis, 114.

Pennycuick, C.J. (1982) The flight of petrels and albatrosses (Procellariiformes), observed in south Georgia and its vicinity. Philosophical Transactions Of The Royal Society London, $\mathbf{3 0 0 .}$ 
Pennycuick, C.J. (1983) Thermal soaring compared in three dissimilar tropical bird species, Fregata magnificens, Pelecanus occidentals and Coragyps atratus. Journal of Experimental Biology, 102, 307-325.

Pennycuick, C.J. \& Scholey, K.D. (1984) Flight behavior of Andean condors Vultur gryphys and turkey vultures Cathartes aura around Paracas Peninsula, Peru. Ibis, 126, 253-256.

Rabenold, P.P. (1987) Recruitment to food in black vultures: evidence for following from communal roosts. Animal Behaviour, 35, 1775-1785.

Richardson, W.J. (1978) Timing and amount of bird migration in relation to weather: a review. Oikos, 30, 224.

Ruxton, G.D. \& Houston, D.C. (2004) Obligate vertebrate scavengers must be large soaring fliers. Journal of Theoretical Biology, 228, 431-436.

Sapir, N., Horvitz, N., Wikelski, M., Avissar, R., Mahrer, Y. \& Nathan, R. (2011) Migration by soaring or flapping: numerical atmospheric simulations reveal that turbulence kinetic energy dictates bee-eater flight mode. Proceedings of the Royal Society B: Biological Sciences, 278, 3380-3386.

Smith, S.A. \& Paselk, R.A. (1986) Olfactory sensitivity of the turkey vulture (Cathartes aura) to three carrion-associated odorants. The Auk, 586-592.

Spaar, R. (1995) Flight behavior of steppe buzzards (Buteo buteo vulpinus) during spring migration in southern Israel: a tracking-radar study. Israel Journal of Zoology, 41, 489-500.

Stager, K.E. (1964) The role of olfaction in food location by turkey vultures. Los Angeles County Museum Contributions in Science, 81, 1-63.

Suryan, R.M., Anderson, D.J., Shaffer, S.A., Roby, D.D., Tremblay, Y., Costa, D.P., Sievert, P.R., Sato, F., Ozaki, K., Balogh, G.R. \& Nakamura, N. (2008) Wind, waves, and wing loading: morphological specialization may limit range expansion of endangered albatrosses. PLoS ONE, 3, e4016.

Weimerskirch, H., Guionnet, T., Martin, J. \& Shaffer, S. (2000) Fast and fuel efficeint? Optimal use of wind by flying albatrosses. Proceedings of the Royal Society B: Biological Sciences, 267, 1869-1874. 


\section{TABLES}

Table 1-1. Vulture's hourly proportionate use of uplift type (thermal, turbulent, linear, soaring) as a response to local weather conditions. Final models include only significant interaction terms.

\begin{tabular}{|c|c|c|c|c|c|c|c|c|c|}
\hline \multirow{3}{*}{$\begin{array}{l}\text { Species } \\
\text { Turkey } \\
\text { vulture }\end{array}$} & & \multicolumn{2}{|c|}{ Turbulent } & \multicolumn{2}{|l|}{ Thermal } & \multicolumn{2}{|l|}{ Linear } & \multicolumn{2}{|l|}{ Glide } \\
\hline & & z-value & $\operatorname{Pr}(>|z|)$ & z-value & $\operatorname{Pr}(>|z|)$ & z-value & $\operatorname{Pr}(>|z|)$ & z-value & $\operatorname{Pr}(>|z|)$ \\
\hline & (Intercept) & -4.6490 & 0.0000 & -4.9260 & 0.0000 & -10.8900 & 0.0000 & -9.7090 & 0.0000 \\
\hline & Humidity & 2.3430 & 0.0192 & 0.3413 & 0.7329 & -0.5615 & 0.5745 & -2.4720 & 0.0134 \\
\hline & Wind Speed & 0.0614 & 0.9511 & 1.3360 & 0.1816 & -2.3530 & 0.0186 & -0.5810 & 0.5612 \\
\hline & Cloud = Overcast & -0.4684 & 0.6395 & -1.4310 & 0.1524 & 0.8865 & 0.3753 & -1.0010 & 0.3166 \\
\hline & Cloud = Partly Cloudy & 0.2015 & 0.8403 & -1.8050 & 0.0711 & 0.3639 & 0.7159 & -1.1380 & 0.2550 \\
\hline & Hour & -0.1173 & 0.9066 & 0.0950 & 0.9243 & -1.3410 & 0.1801 & -2.7500 & 0.0060 \\
\hline & Temperature & -1.9660 & 0.0494 & -1.1220 & 0.2617 & 1.8140 & 0.0698 & 1.9500 & 0.0512 \\
\hline & Overcast X Temperature & -- & -- & 2.4740 & 0.0134 & -- & -- & -- & -- \\
\hline & Partly Cloudy X Temperature & -- & -- & 2.5880 & 0.0096 & -- & -- & -- & -- \\
\hline \multirow{11}{*}{$\begin{array}{l}\text { Black } \\
\text { vulture }\end{array}$} & (Intercept) & -4.8950 & 0.0000 & 2.9480 & 0.0032 & -8.1160 & 0.0000 & -5.2790 & 0.0000 \\
\hline & Humidity & 2.5200 & 0.0117 & 0.9485 & 0.3429 & -0.7981 & 0.4248 & -2.9100 & 0.0036 \\
\hline & Wind Speed & -0.2598 & 0.7950 & 2.7590 & 0.0058 & 0.4586 & 0.6465 & 1.1460 & 0.2518 \\
\hline & Cloud = Overcast & -1.1440 & 0.2527 & -2.9270 & 0.0034 & -1.7180 & 0.0858 & 0.9228 & 0.3561 \\
\hline & Cloud = Partly Cloudy & -0.0780 & 0.9378 & -3.5230 & 0.0004 & -1.5740 & 0.1156 & 2.3930 & 0.0167 \\
\hline & Hour & 2.2130 & 0.0269 & -0.2911 & 0.7710 & 0.4713 & 0.6374 & -1.8180 & 0.0690 \\
\hline & Temperature & -2.8250 & 0.0047 & 0.1848 & 0.8534 & -4.0640 & 0.0000 & 2.0760 & 0.0379 \\
\hline & Overcast X Temperature & -- & -- & -- & -- & 1.6400 & 0.1009 & 0.6067 & 0.5441 \\
\hline & Partly Cloudy X Temperature & -- & -- & -- & -- & 4.2510 & 0.0000 & -2.6490 & 0.0081 \\
\hline & Humidity X Temperature & -- & -- & -2.5470 & 0.0109 & -4.4140 & 0.0000 & -- & -- \\
\hline & Wind X Temperature & -2.3850 & 0.0171 & -- & -- & -- & -- & -- & -- \\
\hline
\end{tabular}




\section{FIGURES}

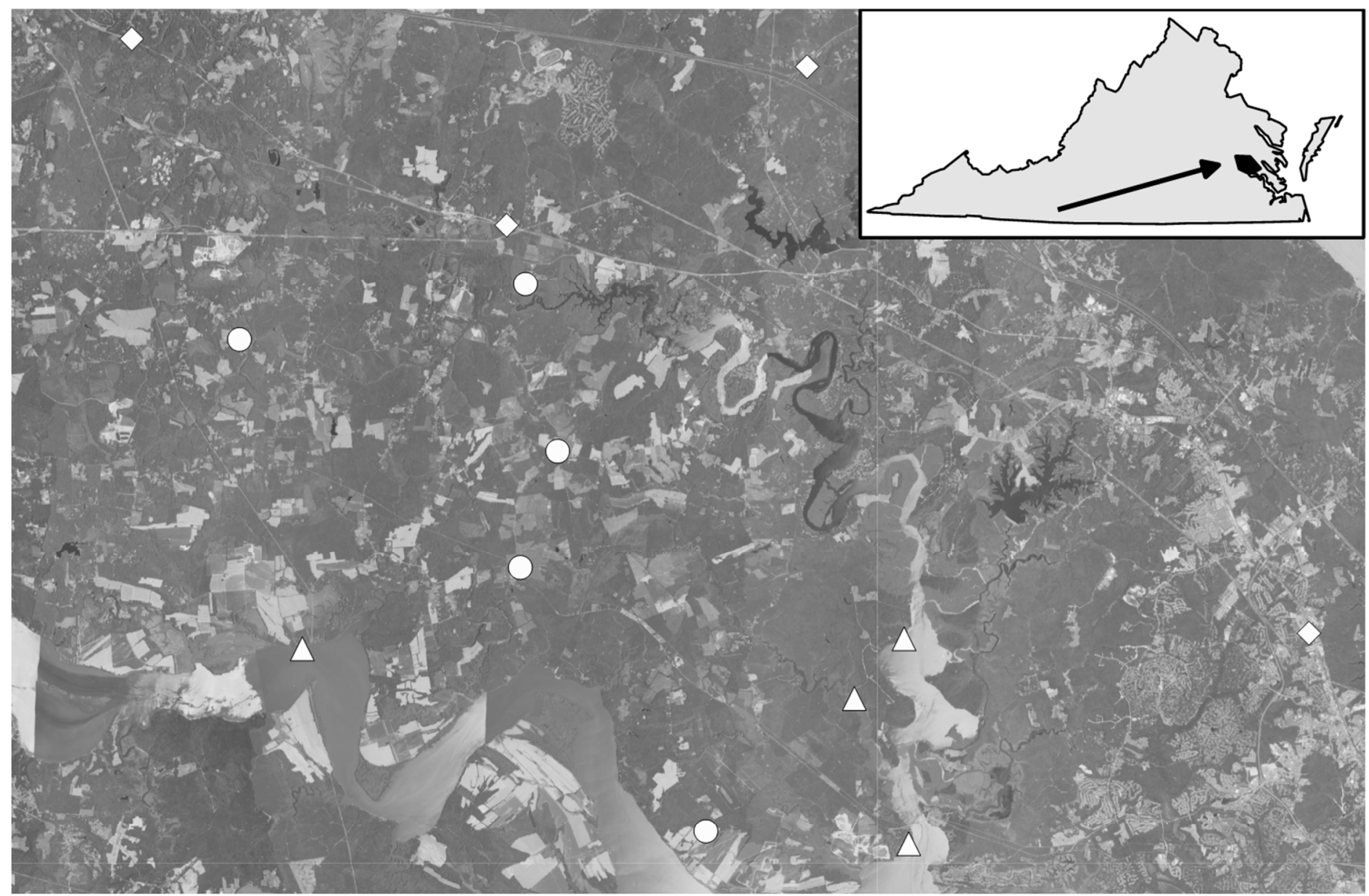

\section{Legend}

Site Landcover Types
$\triangle$ River
$\diamond$ Road
$\bigcirc$ Field

(N)

$\begin{array}{rrrrrr}2.5 & 0 & 2.5 & 5 & 7.5 & 10 \mathrm{~km}\end{array}$ 
Fig.1-1. Map of site locations in and around Charles City County, Virginia. Imagery shown is provided by National Agriculture Imagery Program (NAIP) from 2010.

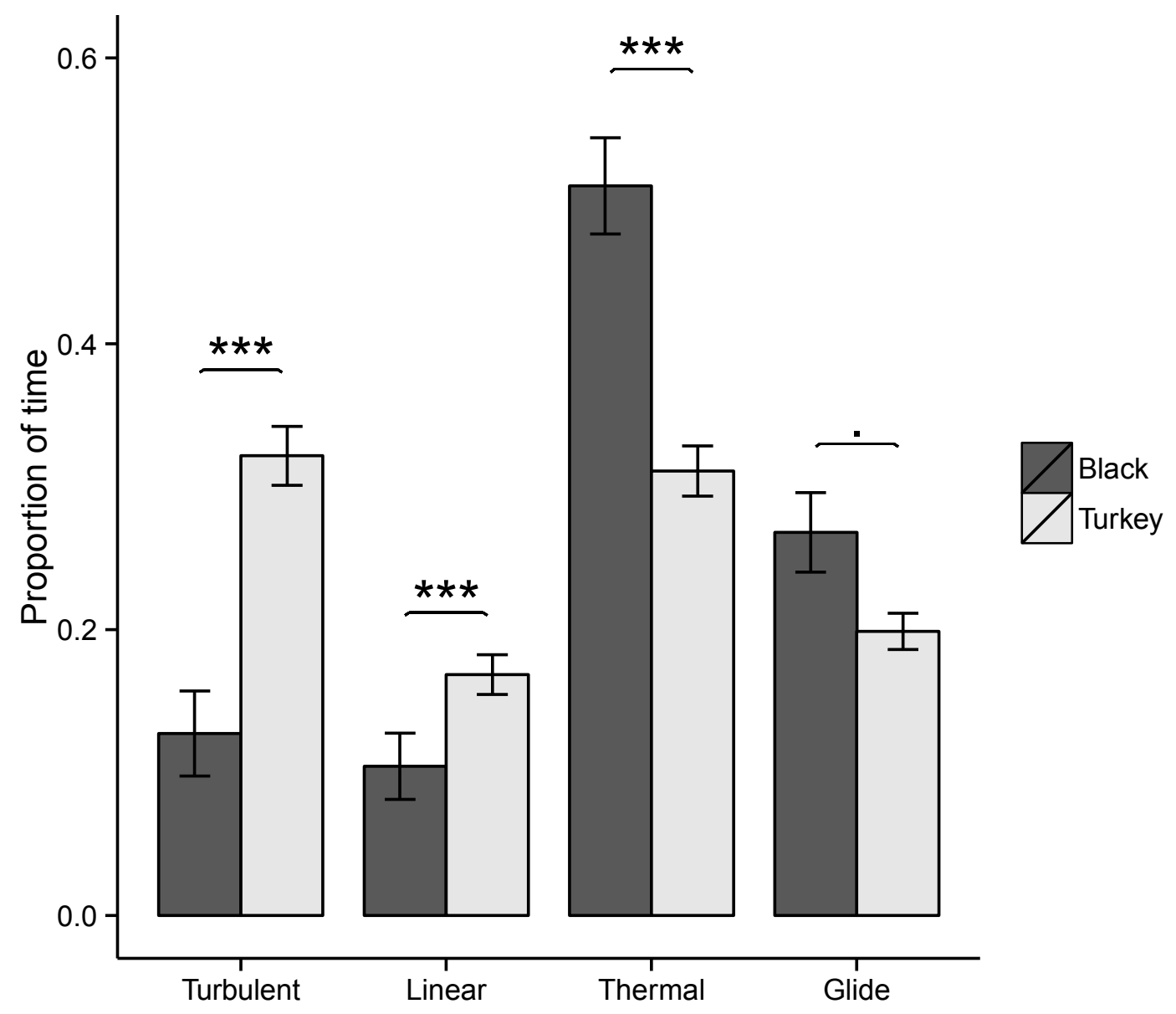

Fig. 1-2. Proportion of time using flight types differed by species (see legend).

Significance of species differences in mean proportion used indicated: $()<0.1,.\left(^{*}\right)<0.05$, $\left({ }^{* *}\right)<0.01,\left(^{* * *}\right)<0.001$. Black vultures used more thermal soaring than turkey vultures and turkey vultures used more turbulent and linear soaring than black vultures. Flapping flight is not included as we did not observe sustained flapping flight by either species. 


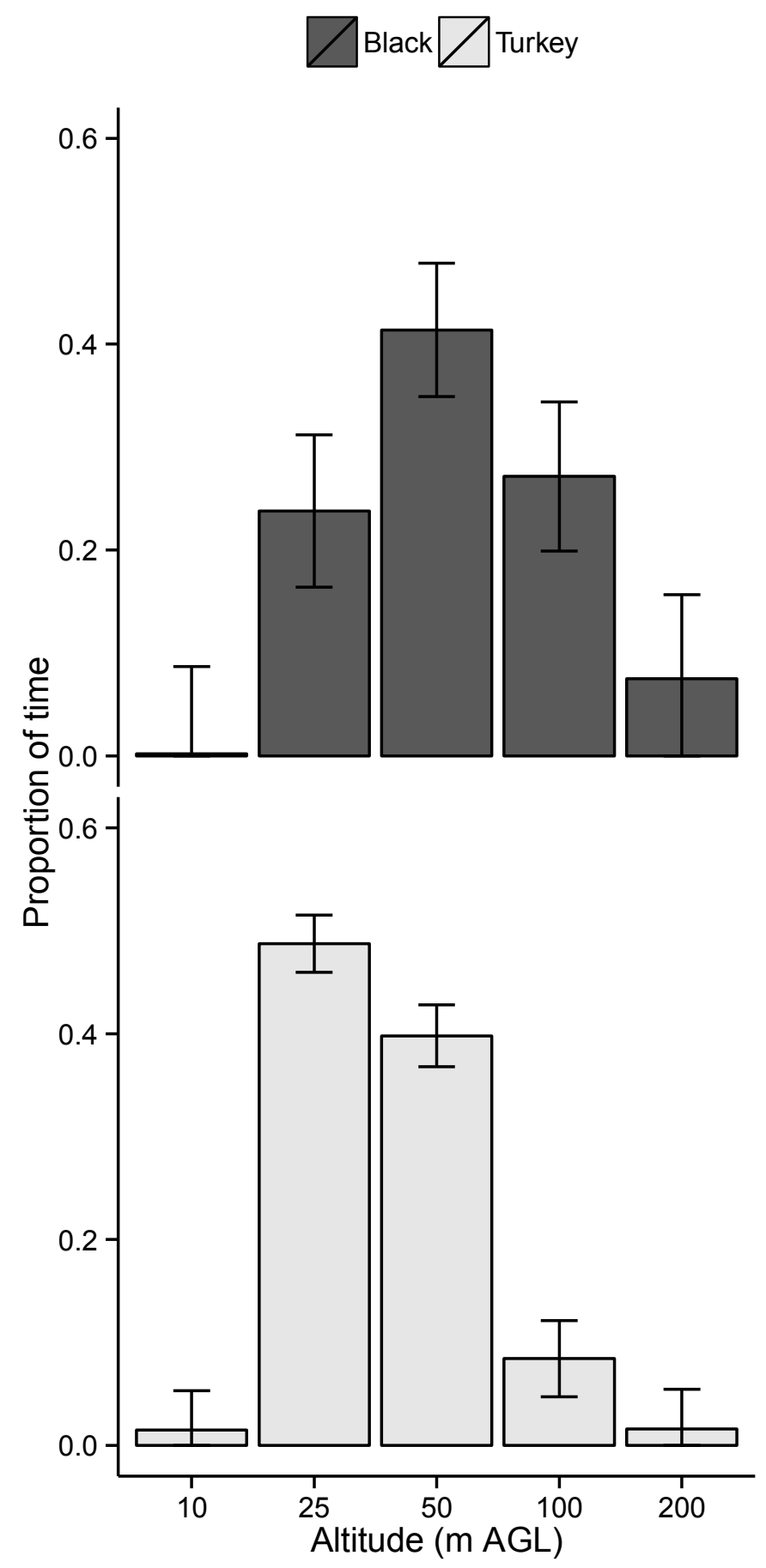

Fig. 1-3. Proportion of time spent in each altitudinal range by species. Altitudinal ranges are: $<10,11-25,26-50,51-100$, and 101-200 m. Turkey vultures spent more time at lower altitudes than black vultures (Wilcox Rank Test: $\mathrm{W}=56718.5$, p-value $<0.0001$ ). 


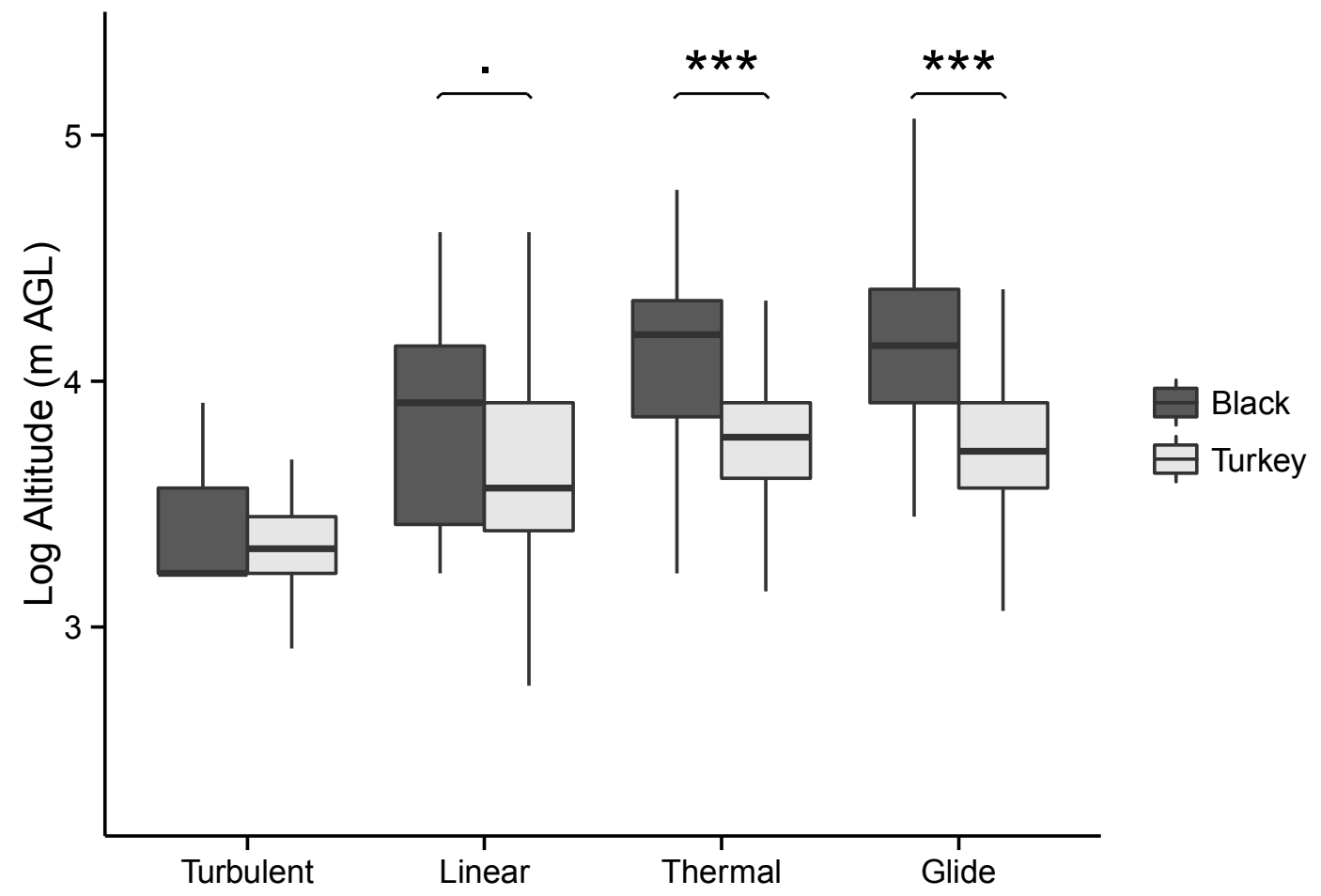

Fig. 1-4. Mean log-transformed altitudes by flight type and species. Altitudes are above ground level (AGL). Significance of species differences in mean altitudes indicated: $()<0.1,.\left({ }^{*}\right)<0.05,\left({ }^{* *}\right)<0.01,\left({ }^{* * *}\right)<0.001$. There was no difference in mean flight altitudes of species using turbulent soaring and marginal difference in mean flight altitudes of species using linear soaring. Black vultures flew significantly higher than turkey vultures when using thermal soaring or gliding. Flapping flight is not included as we did not observe sustained flapping flight by either species. 

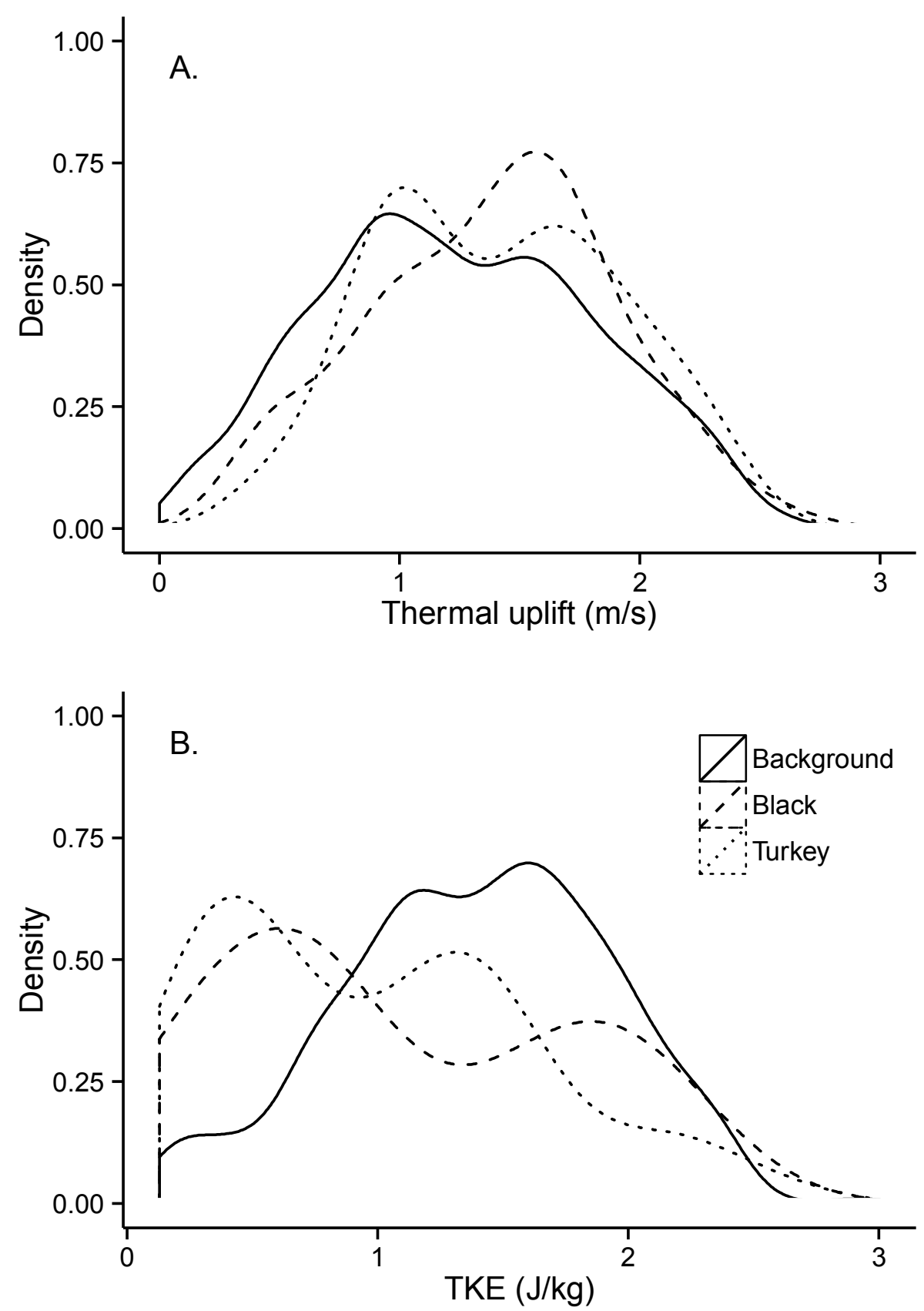

Fig. 1-5. Species use versus estimated background availability of $(A)$ turbulent uplift (TKE; $\mathrm{J} / \mathrm{kg}$ ) and (B) thermal uplift $(\mathrm{m} / \mathrm{s})$. Uplift availabilities estimated from NARR data provided by NCEP and accessed via Movebank's Env-data. Background uplift availability (solid) compared to black vulture (dashed) uplift use and turkey vulture (dotted) uplift use. 


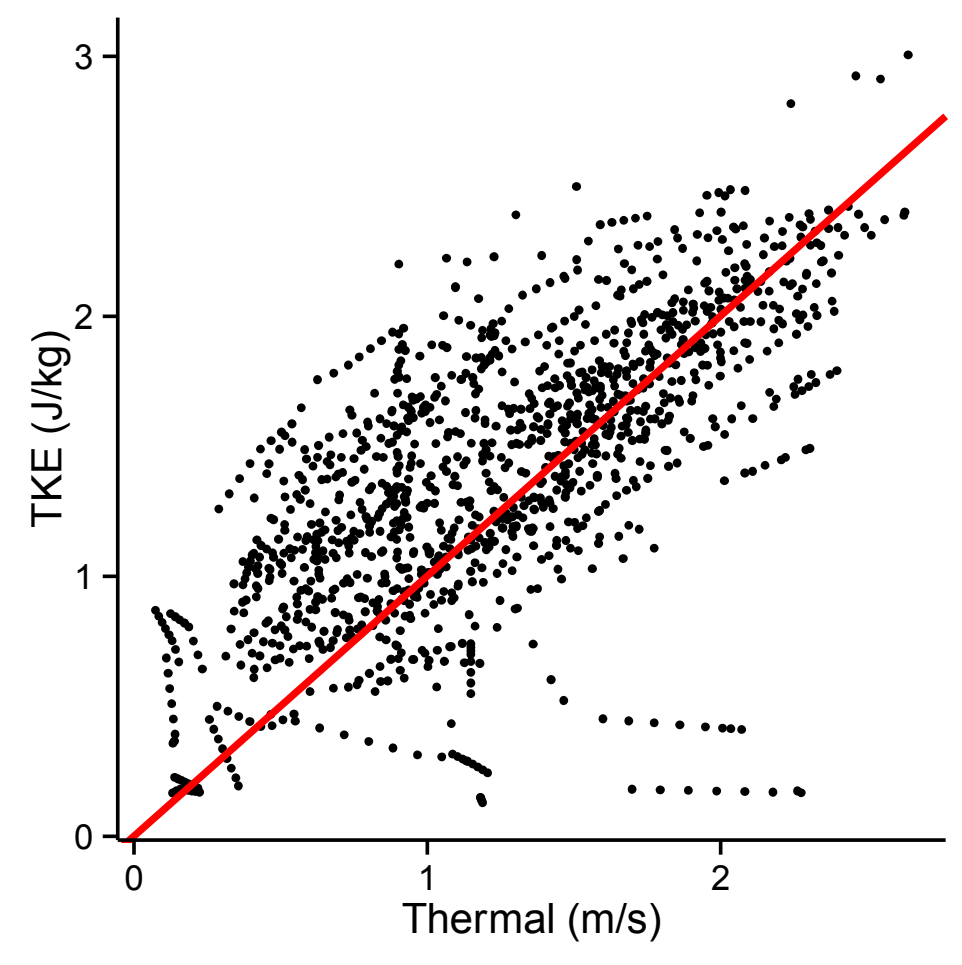

Fig. 1-6. The strengths of modeled TKE $(\mathrm{J} / \mathrm{kg})$ and thermal $(\mathrm{m} / \mathrm{s})$ uplift intensities available during observation periods. TKE and thermal uplift were correlated ( $r=0.6778)$, and therefore are often strong at the same time. 

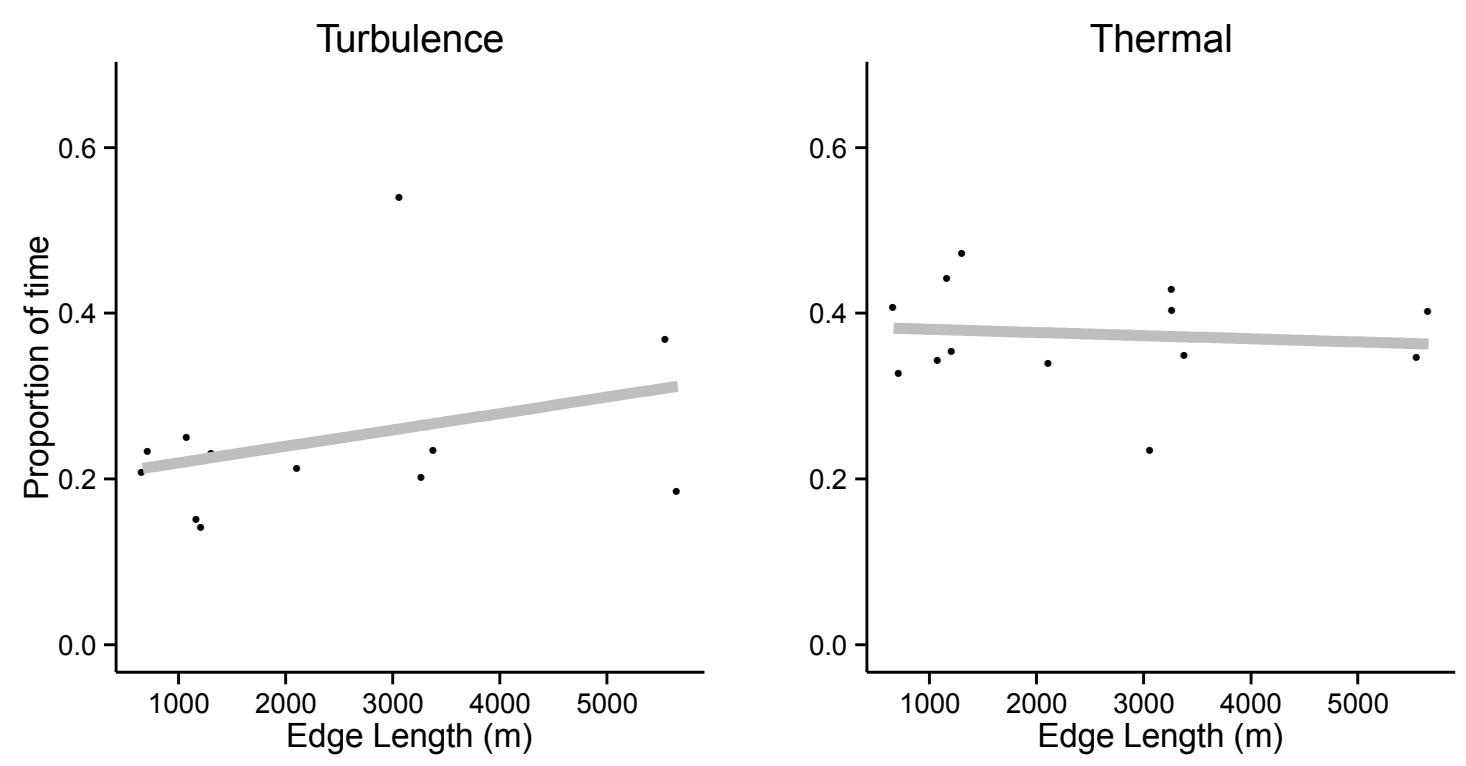

Fig. 1-7. Proportionate use of turbulent and thermal soaring by vultures in response to edge length at sites. Vultures generally increased use of turbulent soaring with forest edge length, but the trend is non-significant $(b=1.981-05$, $t(13)=1.410, p<0.27)$. Neither species varied use of thermal soaring by forest edge length $(b=-3.82 e-06, t(13)=-0.354, p=0.73)$. 


\section{CHAPTER 2}

CONTINENTAL SCALE RESPONSE TO VARIATION IN UPLIFT AVAILABILITY BY NEW WORLD VULTURES 
Julie M. Mallon ${ }^{1}$

Keith L. Bildstein ${ }^{2}$

Todd E. Katzner ${ }^{1,3}$

1 Division of Forestry and Natural Resources, West Virginia University, Morgantown, WV 26506, USA

2 Hawk Mountain Sanctuary, Acopian Center for Conservation Learning, 410 Summer Valley Rd., Orwigsburg, PA 17961, USA

3 United States Geological Survey, Forest and Rangeland Ecosystem Science Center, Boise, ID, USA

\section{ABSTRACT}

Behavioral ecology is rarely studied at a continental scale. Research conducted at smaller scales may be constrained to inference of specific populations or communities. Such single-site work may not detect species behavioral responses to varied environmental conditions across their ranges. Certain patterns of species behavior, therefore, may be most effectively resolved through studies at large spatial scales. To evaluate resource use at the specieslevel, we observed behavioral responses of wide-ranging species to variation in uplift resource availabilities across two continents. We used telemetry data to analyze patterns of overall mean flight altitudes and observational data to record patterns of low altitude $(<200 \mathrm{~m})$ vulture flights. We found that mean flight altitudes decreased with absolute latitude in response to variation of thermal uplift strength. We also found that mean altitudes of low altitude flights decreased with increasing 
availability of turbulent uplift. Patterns of vulture flight altitudes varied in response to climate-scale changes in uplift availabilities.

\section{KEYWORDS}

uplift, black vulture, turkey vulture, soaring, movement ecology, resource use, continental scale

\section{INTRODUCTION}

Understanding how and why animals move is fundamental to understanding their abundances and distributions. Movement patterns change over the course of an animal's lifetime, which influences their ecology (Nathan et al. 2008). Many recent movement studies are of migration, which constrain our understanding to one segment of an animal's life history. Migration is often physically taxing and behaviorally distinct from other life history periods. Studies of both migration and non-migration provide a fuller understanding of the ecological consequences of movement.

To learn about the ecology of flying birds, researchers often look at how they behave in response to environmental variation. Birds can respond to such variation by altering flight type (Spaar and Bruderer 1997, Vansteelant et al. 2014a), timing of movements (Shamoun-Baranes et al. 2006a, La Sorte et al. 2014), speed (Klaassen et al. 2008, 2012, Mandel et al. 2011, Vansteelant et al. 2014b), direction (Mandel et al. 2011), or altitude (Shamoun-Barnes et al. 2006b). Soaring species are sensitive to environmental variation and respond behaviorally 
to meteorological conditions (Spaar et al. 2000; Shannon et al. 2002; ShamounBaranes et al. 2003a,b, Shamoun-Baranes et al. 2006a, 2006b, Mandel et al. 2011).

Soaring birds are limited by the availability of environmentally generated uplift both spatially (Houston 1976, 1983, Suryan et al. 2008) and temporally (Kerlinger and Gauthreaux 1985; Kerlinger 1989; Spaar 1995; Leshem and YomTov 1996; Mandel and Bildstein 2007). Without uplift, birds are grounded or must switch to energy expensive flapping flight. The uplift types and intensities birds can use to soar are further limited by their anatomy and flight mechanics (Houston 1976, 1983, Rosser and George 1986, Meyers and Stakebake 2005, Suryan et al. 2008). It is currently unknown how birds deal with variation in uplift resource availability or intensity across their distributions.

To understand of how avian behavior varies over large geographic scales, we observed flight behavior across the distributions of two wide-ranging, soaring species. Because soaring birds are limited by the type and intensity of available uplift, we hypothesized that soaring flight altitudes of vultures would be driven by the strength and availability of uplift. Using telemetry and observational data collected from two species of Cathartid vulture, black (Coragyps atratus) and turkey vultures (Cathartes aura), we investigated if vulture flight altitude varied with latitude. We predicted vultures would use thermal uplift most in the tropics where solar intensity is greatest and would use turbulent uplift most at the extremes of their ranges where thermal uplift is weaker. 


\section{METHODS}

\section{Study Species}

Turkey vultures (Cathartes aura) are long-distance migrants found nearly everywhere in the Americas, from Tierra de Fuego to Southern Canada (approximately $54 \mathrm{~S}-54 \mathrm{~N}$ ). Turkey vultures are found in many habitats, including deserts, savannah and forests.

Black vultures (Coragyps atratus) are often sympatric with turkey vultures, but have a somewhat smaller geographic range because they are less migratory. Black vultures currently occur from eastern United States south to Southern Chile, but are expanding in range northward (Sauer et al. 2014). Black vultures are most abundant in human-altered landscapes (Hill and Neto 1991), but occur even in interior lowland forests (Mallon et al. 2013).

Both species search for food on the wing for carrion. This means they are often active throughout the day and easily observed in-flight. Both are capable soarers and usually fly without flapping. Cathartid vultures are known to use thermals to soar (Pennycuick 1983, Bohrer et al. 2011) but also use turbulence to soar when they fly close to the ground (Mallon et al. in prep.).

Survey data

We surveyed 91 routes throughout the Americas for black and turkey vultures (Table 2-1). We only chose routes in largely open habitats with good visibility. No surveys were conducted when rain was likely or during periods of active migration. We surveyed locales during the breeding season only at high latitudes where turkey vulture populations are obligate migrants. We surveyed all 
other locales during the breeding and non-breeding seasons (where vultures are present year-round).

We surveyed for vultures between $0900-1700 \mathrm{~h}$ local time. This period corresponds to the time when vultures are most active but are not flying to or from roosts (Kirk and Currall 1994). Local time was recorded every 30 min of surveys. We conducted surveys from a vehicle with 1-2 observers driven at 30-60 km/hr.

When we saw vultures, we recorded their locations to the nearest $0.1 \mathrm{~km}$ or 0.1 mile (depending on the odometer of the vehicle). We estimated the altitude at which they were flying by grouping them into altitudinal ranges $(<10,11-20,21-$ 30,31-50,51-100,101-200 m above ground level (AGL)). For additional details on survey methods, see Bildstein et al. 2007.

Telemetry data

We collected flight altitudinal data from 13 turkey vultures using GPS telemetry units (our sample size for black vultures is too small for reasonable comparison). Turkey vultures were trapped between 2004 and 2014 at three sites in east, central, and western North America (Dodge et al. 2014). We used solarpowered backpack GPS satellite transmitters secured by an $11 \mathrm{~mm}$ Teflon ribbon harness (Bally Ribbon Mills, Bally, PA, USA). Telemetry units were either $70 \mathrm{~g}$ PTT-100 models (Microwave Telemetry, Columbia, MD, USA) programmed to collect GPS locations and altitude above sea level (ASL) every hour or $40 \mathrm{~g}$ Model 40 GPS (Northstar Science and Technology, King George, VA, USA) programmed to collect GPS locations and ASL every three hours. 


\section{Data analyses}

For the purposes of data analysis, we grouped survey routes into "locales" (clusters of routes within a country or group of US states) and "regions" (groups of locales $<300 \mathrm{~km}$ apart; Fig. 2-1). We categorized data by seasons. In the northern hemisphere, "breeding season" was April - October and the "non-breeding season" was November - March. We categorized the seasons oppositely in the southern hemisphere: "breeding season" was November - March and the "nonbreeding season" was April - October. We categorized a telemetered bird as "migratory" when it moved one or more latitudinal degrees away from its breeding or wintering latitude.

To determine if flight behavior was driven by the strength or availability of uplift, we calculated the intensity of turbulent and thermal uplifts at each $\mathrm{km}$ surveyed (odometer readings in miles were converted to $\mathrm{km}$ for analyses). We used turbulent kinetic energy (TKE) at surface pressure $(1000 \mathrm{mb})$ to estimate turbulence intensity near the earth's surface. Thermal uplift $\left(\mathrm{ms}^{-1}\right)$ was provided by Movebank Env-Data and TKE $\left(\mathrm{Jkg}^{-1}\right)$ was provided by North American Regional Reanalysis (NARR) (NOAA's National Center for Atmospheric Prediction (NCEP)) data available via Movebank Env-Data (Dodge et al. 2013). TKE was only available for latitudes $54-12 \mathrm{~N}$ while thermal uplift was available for all latitudes in our analysis.

We used only non-migratory survey data for our analyses. To assess variation in low altitude vulture flights, we compared the proportion of flights at altitudes $<200 \mathrm{~m}$ AGL among survey regions. We also evaluated patterns of low 
altitude flights across their ranges by absolute latitude. We log-transformed the maximum value of altitude range for our calculations of mean flight altitudes. We used species mean flight altitudes at each locale to test for patterns of low flight altitudes by latitude and season.

To have a complete understanding of vulture flight altitudes across their ranges, we evaluated patterns of low and mean flight altitudes concurrently. To do so, we used telemetry data from areas comparable to the regions we surveyed. We used data collected $0900-1600 \mathrm{hr}$ and groundspeed $>0 \mathrm{~km} / \mathrm{hr}$ (to remove perched or incubating birds). We calculated AGL by subtracting local elevation (30 m Aster DEM) from ASL values. To account for errors due to interpolation between points, we used AGL data >-50m (Katzner et al. 2012). We determined mean AGL for each bird at both breeding and non-breeding ground locations.

We evaluated whether the flight altitudes of telemetered birds were driven by uplift intensities, latitude, or season using a linear mixed model. We used logtransformed AGL as the response variable and bird nested within year as our random effect. We compared models of fixed effects including season, thermal uplift intensity, TKE intensity, and latitude. We tested for interactions of these fixed effects with latitude. We used information-theoretic approach to evaluate our models using Akaike's Information Criterion. We present only the final model with the fewest number of interactions. 


\section{RESULTS}

Uplift use and availability

Strong thermals and turbulent uplifts were both available at low latitudes (Fig. 2-2 and 2-3). At temperate latitudes, thermal uplift intensity fluctuated strongly on a seasonal basis. During the breeding season (April - October) thermal intensity was positively related to latitude but during the non-breeding season (November - March) it was negatively related to latitude (Fig. 2-4). TKE decreased with increasing latitude (Fig. 2-4) during both seasons.

\section{Low altitude flight}

We surveyed a total of $20,640 \mathrm{~km}$ of roads over 148 surveys on 91 routes of $57-482 \mathrm{~km}$ in length $(\bar{x}=227 \mathrm{~km})$. During surveys we observed 13,390 turkey vultures and 36,395 black vultures. Of these 3,992 were perched and 46,793 were in flight; we recorded flight altitude estimates of 7,556 individuals. The number of vultures detected during our surveys varied with latitude and season (Table 2-1). Density of both species was greater at lower latitudes and the difference in densities among regions was greater during non-breeding season than the breeding season.

Black vultures flew at the similar altitudes across all latitudes ( $p$-value $=0.8550)$ and during both seasons $(p-v a l u e=0.6610 ;$ Fig. $2-5)$. Turkey vultures increased flight altitude with absolute latitude ( $p$-value $=0.0103$ ) but did not vary flight altitude seasonally (0.8543; Fig. 2-5).

The proportion of turkey vulture flights at altitudes of $<50 \mathrm{~m}$ appeared to increase with TKE intensity (Fig. 2-6) although this trend was not statistically 
significant $(p$-value $=0.211)$. This may have been due to imperfect estimation of TKE by climate model, which have coarse temporal and spatial resolutions and did not capture strong turbulence associated with microhabitat features (Mallon et al. in prep.). TKE, however, should be a sufficient measure to detect changes in turbulent activity over the large spatial scales in our study.

The proportion of black vulture flights at low altitudes did not respond to TKE intensity ( $p$-value $=0.858$ ). Across all regions, black vultures spent most of the time >50 m AGL but flew lower more frequently in the Eastern and Southeastern US regions (Fig. 2-7). Turkey vultures generally spent the greatest proportion of time in flight at $<50 \mathrm{~m}$ but increased the proportion of flights at $<50 \mathrm{~m}$ in low latitude regions. Turkey vultures spent the smallest proportion of time $<50 \mathrm{~m}$ in Canada, Midwest US, and Eastern US - three of the four regions furthest from the equator. The largest proportion of low altitude flights was observed in Northern South America, the latitudinal center of the species distribution.

\section{Mean altitude flight}

Twelve of the telemetered birds were migrants and one bird was a nonmigrant that occupied only one region. We had data from both breeding and nonbreeding seasons for seven of thirteen telemetered turkey vultures (Table 2-2). Overall, turkey vultures flew lower further from the equator at high TKE intensities, but flew higher as thermal uplift intensity increased (Table 2-3).

\section{DISCUSSION}

Vulture flight altitudes differed throughout their ranges in response to the availability of thermal and turbulent uplifts. Intensity of thermal uplift has repeatedly 
been shown to drive flight altitudes of soaring birds (Pennycuick 1972; Spaar 1995; Spaar et al. 2000; Shannon et al. 2002; Shamoun-Baranes et al. 2003a, 2003b). By combining telemetry and observational data, we were better able to evaluate flight behavior patterns. We found that availability of uplift varied globally with latitude.

Turkey vultures flew highest at low latitudes where solar intensity and thermal development were high (Fig. 2-2). It is known that summer insolation is positively correlated with latitude (Hinrichs and Kleinbach 2012), which explains the increase in thermal intensity with distance from the equator during the breeding season. Although thermal intensity was higher at breeding grounds than wintering grounds, turkey vultures still flew lower at high latitudes (Table 2-3). This pattern could arise if maximum thermal height was lower at high latitudes or because vultures soar at lower overall heights while foraging on their breeding grounds.

Although turkey vultures flew lower at the northern extent of their range, they did not use turbulent uplift as an alternative to thermal uplift. Turbulent soaring by turkey and black vultures occurs at altitudes $<50 \mathrm{~m}$ AGL (Mallon et al. in prep.) where turbulence is strongest. During our Canada surveys, however, the mean altitudes of low flying turkey vultures exceeded 50 m AGL (mean AGL: 58 - 100 m; Fig. 2-5), indicating that vultures use proportionately less turbulent uplift here than they do in lower latitude regions. At the northern extent of their breeding distribution, turkey vultures' near-exclusive use of thermal uplift appears to be a consequence of turbulent uplift being largely unavailable (Fig. 2-3). 
Differences in use of uplift by birds that forage on the wing should ultimately result in differences in use of food resources. Turkey vultures increased the frequency of low altitude flights near the equator (Fig. 2-7); this pattern was consistent with the increase in turbulent uplift availability near the equator (Fig. 23). The median flight altitude of turkey vultures deviated from the general pattern in Southern and Central South America, where we suspect turkey vultures were responding to the high abundance of black vultures by soaring low.

By soaring at low altitudes using turbulent uplift turkey vultures should increase their effectiveness at detecting carrion via olfaction (Stager 1964, Smith and Paselk 1986). Olfaction increases the detection of small or concealed carrion that would be missed by visual detection from higher altitudes. Turkey vulture diets should have a greater proportion of small or concealed carrion at lower latitudes where turbulent uplift is strongest (Fig. 2-4). When turbulent uplift is unavailable, turkey vultures must increase their foraging efforts while thermalling. Turkey vultures that forage using thermal uplift will select proportionately more large carrion in more open or predictable habitats. Therefore, by changing the proportions of uplifts they use across their distributions, turkey vultures will consequently change the carrion resources they use.

Black vultures, in contrast, should not select different carrion types throughout their range. They invariantly soar at higher altitudes (Fig 2-5 and 2-7) using thermal uplift (Mallon et al. in prep.), where they can simultaneously follow low-flying turkey vultures to carrion (Buckley 1996, Rabenold 1987) and forage for 
large carrion that will feed multiple scavengers (Stewart 1978, Coleman and Frazer 1987, Rabenold 1987). Black vultures use thermal soaring and a visual foraging strategy, and should not use carrion different from its availability across their range.

Observed flight altitude patterns were consistent with the availabilities of uplift intensities. The differences in uplift availability at breeding and wintering grounds may result in different movement patterns. Dodge et al. (2014) found turkey vulture breeding ranges increased with temperature and suggested vultures were taking advantage of increased uplift availability in the form of thermals. In contrast, previous studies have investigated variation in the sizes of turkey vulture breeding and wintering grounds (DeVault et al. 2004, Houston et al. 2011, Hedlin et al. 2013) and Hedlin et al. (2013) and found that winter ranges are greater in size than breeding ranges, indicating an increased mobility during winter. Although central nesting sites were likely a contributing factor, it is unknown how climate and uplift differed between breeding and non-breeding grounds in these studies.

Competition and resource availability, in addition to uplift availability, should influence mobility. Competition due to increased abundance of vultures during the non-breeding season may require increased foraging effort. Increased abundance, however, should also increase social facilitation of finding carrion. Increased frequency of landing during the non-breeding season would indicate increased use of social facilitation to find carrion. Foraging effort and range size should decrease when environmental productivity is high (Dodge et al. 2014). In the tropics, vultures 
are able to soar at a low cost using multiple uplift types and should not be restricted by uplift availability. Changes in movement patterns (e.g. direction, tortuosity, altitudes) between seasons would indicate that differences in uplift influence mobility. At their breeding grounds, maximizing inter-thermal distance may be more important to vultures where there is less turbulent uplift to use as an alternative and may restrict their mobility.

\section{CONCLUSION}

Understanding how the availability of uplift types affect behavior of soaring species is essential to understand movement behavior. Previous studies have concluded that uplift availability has implications on the movements of migratory soaring birds (Bohrer et al. 2011, Shamoun-Baranes et al. 2003b). While it is clear that birds respond to external factors, internal drivers such as breeding status (Shannon et al. 2002) or migration status (Katzner et al. 2012) may also affect flight behavior. Turkey vulture migration has been well studied (Mandel et al. 2008, 2011, Bohrer et al. 2011, Dodge et al. 2014) but there is relatively less known about the flight behavior of these species during non-migratory flights. Our work demonstrates the importance of studying non-migratory flight behavior in order to have a full account of a species' ecology. We found that turkey vultures flight altitudes varied according to relative thermal and turbulent uplift availabilities. Our findings suggest that the opportunistic soaring and foraging behaviors of turkey vultures are the key to their success as one of the most wide ranging and numerous extant raptor species. 
Migratory and wide-ranging species are increasingly being studied using geospatial technologies such as GPS telemetry (Hebblewhite and Haydon 2010). While this technology provides an accurate representation of individual movements, the margin of error was too great for the focus of our study. Direct observation was necessary to accurately estimate altitudes of low flying birds. Using telemetry data concurrently with observational data was essential to detecting small changes in low flight altitudes over a large geographic range. We were able to differentiate among flights at very low altitudes more confidently using observational data than telemetry data. Other studies have successfully used multiple data types to account for biases associated with remote or sensing technologies (e.g. Spaar and Bruderer 1996). Therefore, we stress the importance of combining multiple data types for a more accurate account of flight behavior.

\section{ACKNOWLEDGEMENTS}

Hawk Mountain Sanctuary and the Burket-Plack Foundation provided funding for this project. David Barber maintained data used in our analyses.

\section{LITERATURE CITED}

Bildstein, K.L., Bechard, M.J., Porras, P., Campo, E. \& Farmer, C.J. (2007) Seasonal abundances and distributions of black vultures (Coragyps atratus) and turkey vultures (Cathartes aura) in costa rica and panama: evidence for reciprocal migration in the Neotropics. Neotropical Raptors, Hawk Mountain Sanctuary, Orwigsburg, PA USA. 
Bohrer, G., Brandes, D., Mandel, J.T., Bildstein, K.L., Miller, T.A., Lanzone, M., Katzner, T., Maisonneuve, C. \& Tremblay, J.A. (2011) Estimating updraft velocity components over large spatial scales: contrasting migration strategies of golden eagles and turkey vultures: Contrasting migration strategies of two raptors. Ecology Letters, 15, 96-103.

Buckley, N.J. (1996) Food finding and the influence of information, local enhancement, and communal roosting on foraging success of North American vultures. The Auk, 113, 473-488.

Coleman, J.S. \& Fraser, J.D. (1987) Food habits of black and turkey vultures in Pennsylvania and Maryland. The Journal of Wildlife Management, 51, 733.

DeVault, T.L., Reinhart, B.D., Brisbin Jr, I.L. \& Rhodes Jr, O.E. (2004) Home ranges of sympatric black and turkey vultures in South Carolina. The Condor, 106, 706-711.

Dodge, S., Bohrer, G., Bildstein, K., Davidson, S.C., Weinzierl, R., Bechard, M.J., Barber, D., Kays, R., Brandes, D., Han, J. \& Wikelski, M. (2014) Environmental drivers of variability in the movement ecology of turkey vultures (Cathartes aura) in North and South America. Philosophical Transactions of the Royal Society B: Biological Sciences, 369, 2013019520130195.

Dodge, S., Bohrer, G., Weinzierl, R., Davidson, S.C., Kays, R., Douglas, D., Cruz, S., Han, J., Brandes, D. \& Wikelski, M. (2013) The environmental-data automated track annotation (Env-DATA) system: linking animal tracks with environmental data. Movement Ecology, 1, 3.

Hebblewhite, M. \& Haydon, D.T. (2010) Distinguishing technology from biology: a critical review of the use of GPS telemetry data in ecology. Philosophical Transactions of the Royal Society B: Biological Sciences, 365, 2303-2312. 
Hedlin, E.M., Houston, C.S., McLoughlin, P.D., Bechard, M.J., Stoffel, M.J., Barber, D.R. \& Bildstein, K.L. (2013) Winter ranges of migratory turkey vultures in Venezuela. Journal of Raptor Research, 47, 145-152.

Hill III, J.R. \& Neto, P.S. (1991) Black vultures nesting on skyscrapers in southern Brazil. Journal of Field Ornithology, 173-176.

Hinrichs, R. \& Kleinbach, M. (2012) Energy: its use and the environment, Cengage Learning.

Houston, C.S., McLoughlin, P.D., Mandel, J.T., Bechard, M.J., Stoffel, M.J., Barber, D.R. \& Bildstein, K.L. (2011) Breeding home ranges of migratory turkey vultures near their northern limit. The Wilson Journal of Ornithology, 123, 472-478.

Houston, D.C. (1976) Breeding of the white-backed and Rüppell's griffon vultures, Gyps africanus and G. rueppellii. Ibis, 118, 14-40.

Houston, D.C. (1983) The adaptive radiation of the griffon vultures. Vulture Biology and Management, California University Press, Los Angeles.

Katzner, T.E., Brandes, D., Miller, T., Lanzone, M., Maisonneuve, C., Tremblay, J.A., Mulvihill, R. \& Merovich, G.T. (2012) Topography drives migratory flight altitude of golden eagles: implications for on-shore wind energy development. Journal of Applied Ecology, 49, 1178-1186.

Kerlinger, P. (1989) Flight Strategies of Migrating Hawks, University of Chicago, Chicago, Illinois.

Kerlinger, P. \& Gauthreaux, S.A. (1985) Flight behavior of raptors during spring migration in south Texas studied with radar and visual observations. Journal of Field Ornithology, 394-402. 
Kirk, D.A. \& Currall, J.E.P. (1994) Habitat associations of migrant and resident vultures in central Venezuela. Journal of Avian Biology, 25, 327-337.

Klaassen, R.H.G., Ens, B.J., Shamoun-Baranes, J., Exo, K.-M. \& Bairlein, F. (2012) Migration strategy of a flight generalist, the lesser black-backed gull Larus fuscus. Behavioral Ecology, 23, 58-68.

Klaassen, R.H.G., Strandberg, R., Hake, M. \& Alerstam, T. (2008) Flexibility in daily travel routines causes regional variation in bird migration speed. Behavioral Ecology and Sociobiology, 62, 1427-1432.

Leshem, Y. \& Yom-Tov, Y. (1996) The use of thermals by soaring migrants. Ibis, 138, 667-674.

Mallon, J.M., Swing, K. \& Mosquera, D. (2013) Neotropical vulture scavenging succession at a capybara carcass in eastern Ecuador. Ornitologia Neotropical, 24, 475-480.

Mandel, J.T., Bildstein, K.L., Bohrer, G. \& Winkler, D.W. (2008) Movement ecology of migration in turkey vultures. Proceedings of the National Academy of Sciences, 105, 19102-19107.

Mandel, J.T., Bohrer, G., Winkler, D.W., Barber, D.R., Houston, C.S. \& Bildstein, K.L. (2011) Migration path annotation: cross-continental study of migrationflight response to environmental conditions. Ecological Applications, 21, 2258-2268.

Mandel, J.T. \& Bildstein, K.L. (2007) Turkey vultures use anthropogenic thermals to extend their daily activity period. Wilson Journal of Ornithology, 119.

Meyers, R.A. \& Stakebake, E.F. (2005) Anatomy and histochemistry of spreadwing posture in birds. 3. Immunohistochemistry of flight muscles and the "shoulder lock" in albatrosses. Journal of Morphology, 263, 12-29. 
Nathan, R., Getz, W.M., Revilla, E., Holyoak, M., Kadmon, R., Saltz, D. \& Smouse, P.E. (2008) A movement ecology paradigm for unifying organismal movement research. Proceedings of the National Academy of Sciences of the United States of America, 105, 19052-19059.

Pennycuick, C.J. (1972) Soaring behavior and performance of some east African birds observed from a motor glider. Ibis, 114.

Pennycuick, C.J. (1983) Thermal soaring compared in three dissimilar tropical bird species, Fregata magnificens, Pelecanus occidentals and Coragyps atratus. Journal of Experimental Biology, 102, 307-325.

Rabenold, P.P. (1987) Recruitment to food in black vultures: evidence for following from communal roosts. Animal Behaviour, 35, 1775-1785.

Rosser, B.W. \& George, J.C. (1986) Slow muscle fibres in the pectoralis of the turkey vulture (Cathartes aura): an adaptation for soaring flight. Zoologischer Anzeiger, 217, 252-258.

Sauer, J.R., Hines, J.E., Fallon, J.E., Pardieck, K.L., Ziolkowski Jr., D.J. \& Link, W.A. (2014) The north American breeding bird survey, results and analysis 1966 - 2013., USGS Patuxent Wildlife Research Center, Laurel, MD.

Shamoun-Baranes, J., Baharad, A., Alpert, P., Berthold, P., Yom-Tov, Y., Dvir, Y. \& Leshem, Y. (2003a) The effect of wind, season and latitude on the migration speed of white storks Ciconia ciconia, along the eastern migration route. Journal of Avian Biology, 34, 97-104.

Shamoun-Baranes, J., Leshem, Y., Yom-Tov, Y. \& Liechti, O. (2003b) Differential use of thermal convection by soaring birds over central Israel. The Condor, 105, 208-218. 
Shamoun-Baranes, J., van Loon, E., Alon, D., Alpert, P., Yom-Tov, Y. \& Leshem, Y. (2006a) Is there a connection between weather at departure sites, onset of migration and timing of soaring-bird autumn migration in Israel? Global Ecology and Biogeography, 15, 541-552.

Shamoun-Baranes, J., van Loon, E., van Gasteren, H., van Belle, J., Bouten, W. \& Buurma, L. (2006b) A comparative analysis of the influence of weather on the flight altitudes of birds. Bulletin of the American Meteorological Society, 87, 47-61.

Shannon, H.D., Young, G.S., Yates, M.A., Fuller, M.R. \& Seegar, W.S. (2002) American white pelican soaring flight times and altitudes relative to changes in thermal depth and intensity. The Condor, 104, 679.

Smith, S.A. \& Paselk, R.A. (1986) Olfactory sensitivity of the turkey vulture (Cathartes aura) to three carrion-associated odorants. The Auk, 586-592.

La Sorte, F.A., Fink, D., Hochachka, W.M., DeLong, J.P. \& Kelling, S. (2014) Spring phenology of ecological productivity contributes to the use of looped migration strategies by birds. Proceedings of the Royal Society B: Biological Sciences, 281, 20140984-20140984.

Spaar, R. (1995) Flight behavior of steppe buzzards (Buteo buteo vulpinus) during spring migration in southern Israel: a tracking-radar study. Israel Journal of Zoology, 41, 489-500.

Spaar, R. \& Bruderer, B. (1997) Migration by flapping or soaring: flight strategies of marsh, montagu's and pallid harriers in southern Israel. Condor, 458-469.

Spaar, R. \& Bruderer, B. (1996) Soaring migration of steppe eagles Aquila nipalensis in southern Israel: flight behaviour under various wind and thermal conditions. Journal of Avian Biology, 27, 289. 
Spaar, R., Liechti, F. \& Bruderer, B. (2000) Forecasting flight altitudes and soaring performance of migrating raptors by the altitudinal profile of atmospheric conditions. Technical Soaring, 24, 49-55.

Stager, K.E. (1964) The role of olfaction in food location by turkey vultures. Los Angeles County Museum Contributions in Science, 81, 1-63.

Stewart, P.A. (1978) Behavioral interactions and niche separation in black and turkey vultures. The Living Bird, 17, 79-84.

Suryan, R.M., Anderson, D.J., Shaffer, S.A., Roby, D.D., Tremblay, Y., Costa, D.P., Sievert, P.R., Sato, F., Ozaki, K., Balogh, G.R. \& Nakamura, N. (2008) Wind, waves, and wing loading: morphological specialization may limit range expansion of endangered albatrosses. PLoS ONE, 3, e4016.

Vansteelant, W.M.G., Bouten, W., Klaassen, R.H.G., Koks, B.J., Schlaich, A.E., van Diermen, J., van Loon, E.E. \& Shamoun-Baranes, J. (2014a) Regional and seasonal flight speeds of soaring migrants and the role of weather conditions at hourly and daily scales. Journal of Avian Biology, 45,01-15.

Vansteelant, W.M.G., Verhelst, B., Shamoun-Baranes, J., Bouten, W., van Loon, E.E. \& Bildstein, K.L. (2014b) Effect of wind, thermal convection, and variation in flight strategies on the daily rhythm and flight paths of migrating raptors at Georgia's Black Sea coast. Journal of Field Ornithology, 85, 4055. 


\section{TABLES}

Table 2-1.List of regions and locales surveyed during breeding (BS) and non-breeding (NBS) seasons. Rate of birds encountered varied by latitude and season.

\begin{tabular}{|c|c|c|c|c|c|c|c|c|c|}
\hline \multirow[b]{2}{*}{ Region } & \multirow[b]{2}{*}{ Locale } & \multirow[b]{2}{*}{$\begin{array}{l}\text { Mean } \\
\text { Lat }\end{array}$} & \multirow[b]{2}{*}{ \# Routes } & \multirow[b]{2}{*}{$\begin{array}{l}\text { BS Survey } \\
\text { date }\end{array}$} & \multirow[b]{2}{*}{$\begin{array}{l}\text { NBS } \\
\text { Survey } \\
\text { date }\end{array}$} & \multirow[b]{2}{*}{$\begin{array}{l}\text { Routes } \\
\text { total } \\
\text { length }(\mathrm{km})\end{array}$} & \multicolumn{3}{|c|}{ Birds per km } \\
\hline & & & & & & & Total & BS & NBS \\
\hline Canada & British Columbia & 50 & 5 & Apr-05 & NA & 1074 & 0.04 & 0.04 & NA \\
\hline \multirow[t]{2}{*}{ Central US } & KA, NB, IA, MO states & 40 & 7 & Jul-08 & NA & 2083 & 0.30 & 0.3 & NA \\
\hline & PA, NY states & 42 & 2 & Jun-05 & Dec-05 & 482 & 0.04 & 0.07 & 0 \\
\hline \multirow[t]{2}{*}{ Eastern US } & VA, WV states & 39 & 2 & Aug-06 & Feb-06 & 410 & 0.26 & 0.33 & 0.20 \\
\hline & WV, VA, TN, NC states & 37 & 5 & Jul-09 & NA & 1545 & 0.22 & 0.22 & NA \\
\hline \multirow{2}{*}{ Southeast US } & SC state & 33 & 5 & Aug-05 & Feb-06 & 1173 & 0.51 & 0.26 & 0.77 \\
\hline & GA, FL states & 32 & 5 & Jun-08 & Feb-08 & 1320 & 0.60 & 0.41 & 0.79 \\
\hline \multirow{2}{*}{ Central America } & Panama & 9 & 6 & Jun-05 & Dec-05 & 963 & 6.48 & 4.88 & 8.07 \\
\hline & Costa Rica & 10 & 9 & Jul-05 & Feb-05 & 1857 & 2.54 & 3.03 & 2.11 \\
\hline Northern South & Eastern Venezuela & 9 & 7 & May-07 & Jan-07 & 1733 & 1.72 & 0.89 & 2.69 \\
\hline America & Western Venezuela & 9 & 8 & Aug-06 & Jan-06 & 1856 & 5 & 4.03 & 5.73 \\
\hline \multirow{3}{*}{$\begin{array}{l}\text { Central South } \\
\text { America }\end{array}$} & Uruguay & -33 & 5 & Dec-09 & Jun-09 & 1181 & 0.21 & 0.34 & 0.08 \\
\hline & Chile & -32 & 5 & Dec-08 & Aug-08 & 1152 & 0.27 & 0.34 & 0.20 \\
\hline & Argentina & -32 & 7 & Feb-07 & Jun-06 & 1988 & 0.40 & 0.17 & 0.56 \\
\hline $\begin{array}{l}\text { Southern } \\
\text { South America }\end{array}$ & Northern Patagonia & -41 & 7 & Dec-07 & NA & 1823 & 0.18 & 0.18 & NA \\
\hline
\end{tabular}


Table 2-2. Summary data of turkey vultures used in telemetry analyses. Breeding or non-breeding locations and latitudes used in analyses are included. Locations were excluded from analyses if were not geographically similar to regions surveyed. Bird indicated with a * was non-migratory and occupied the same region year-round. The number of days birds were tracked varied among individuals and by date of capture.

\section{NON-BREEDING}

$\begin{array}{lllll}\text { Bird } & \text { Location } & \text { Latitude } & \text { Years } & \begin{array}{l}\text { \# days } \\ \text { tracked }\end{array} \\ 127778 & \text { Central America } & 10 \mathrm{~N} & 2013-2014 & 155 \\ 127772 & \text { Central America } & 15 \mathrm{~N} & 2013-2014 & 153 \\ 52069 & \text { Southeast US } & 30 \mathrm{~N} & 2009-2011 & 201 \\ 127774 & \text { Central America } & 13 \mathrm{~N} & 2013-2014 & 146 \\ 127780 & \text { Northern South America } & 8 \mathrm{~N} & 2013-2014 & 127 \\ 52067^{*} & \text { Eastern US } & 41 \mathrm{~N} & 2009-2014 & 286 \\ 127777 & \text { Central America } & 9 \mathrm{~N} & 2013-2014 & 115 \\ 135431 & \text { Northern South America } & 7 \mathrm{~N} & 2009-2014 & 390 \\ 127775 & \text { Central America } & 19 \mathrm{~N} & 2013-2014 & 41 \\ 127781 & \text { Northern South America } & 4 \mathrm{~N} & 2013-2014 & 121 \\ 127779 & \text { Central America } & 11 \mathrm{~N} & 2013-2014 & 107 \\ 57956 & \text { Central America } & 26 \mathrm{~N} & 2009-2010 & 136 \\ \text { BREEDING } & & & \\ 127778 & \text { Canada } & 49 \mathrm{~N} & 2013-2014 & 192 \\ 52069 & \text { Eastern US } & 39 \mathrm{~N} & 2004-2014 & 473 \\ 127780 & \text { Canada } & 53 \mathrm{~N} & 2013-2014 & 222 \\ 52067^{*} & \text { Eastern US } & 41 \mathrm{~N} & 2009-2014 & 657 \\ 135431 & \text { Canada } & 54 \mathrm{~N} & 2009-2014 & 605 \\ 127781 & \text { Canada } & 53 \mathrm{~N} & 2013-2014 & 77 \\ 57956 & \text { Canada } & 46 \mathrm{~N} & 2006-2010 & 67 \\ 139250 & \text { Canada } & 47 \mathrm{~N} & 2014 & 63\end{array}$


Table 2-3. Linear mixed model summary for altitude above ground level (AGL) of telemetered turkey vultures. Turkey vultures $(n=13)$ ranged from lower Canada and eastern USA in the breeding season to Northern South America in the non-breeding season. Values shown are for the final model. TKE and thermal uplift intensities are provided by North American Regional Reanalysis (NARR).

\begin{tabular}{|l|l|l|l|}
\hline Fixed effects & Estimate & Std. Error & $\mathrm{t}$-value \\
\hline Intercept & 4.6000 & 0.0776 & 59.25 \\
\hline Thermal uplift intensity & 0.1870 & 0.2167 & 8.63 \\
\hline Latitude & -0.0095 & 0.0013 & -7.04 \\
\hline TKE intensity & -0.0706 & 0.0287 & -2.46 \\
\hline Latitude:TKE & -0.0027 & 0.0008 & -3.51 \\
\hline
\end{tabular}




\section{FIGURES}

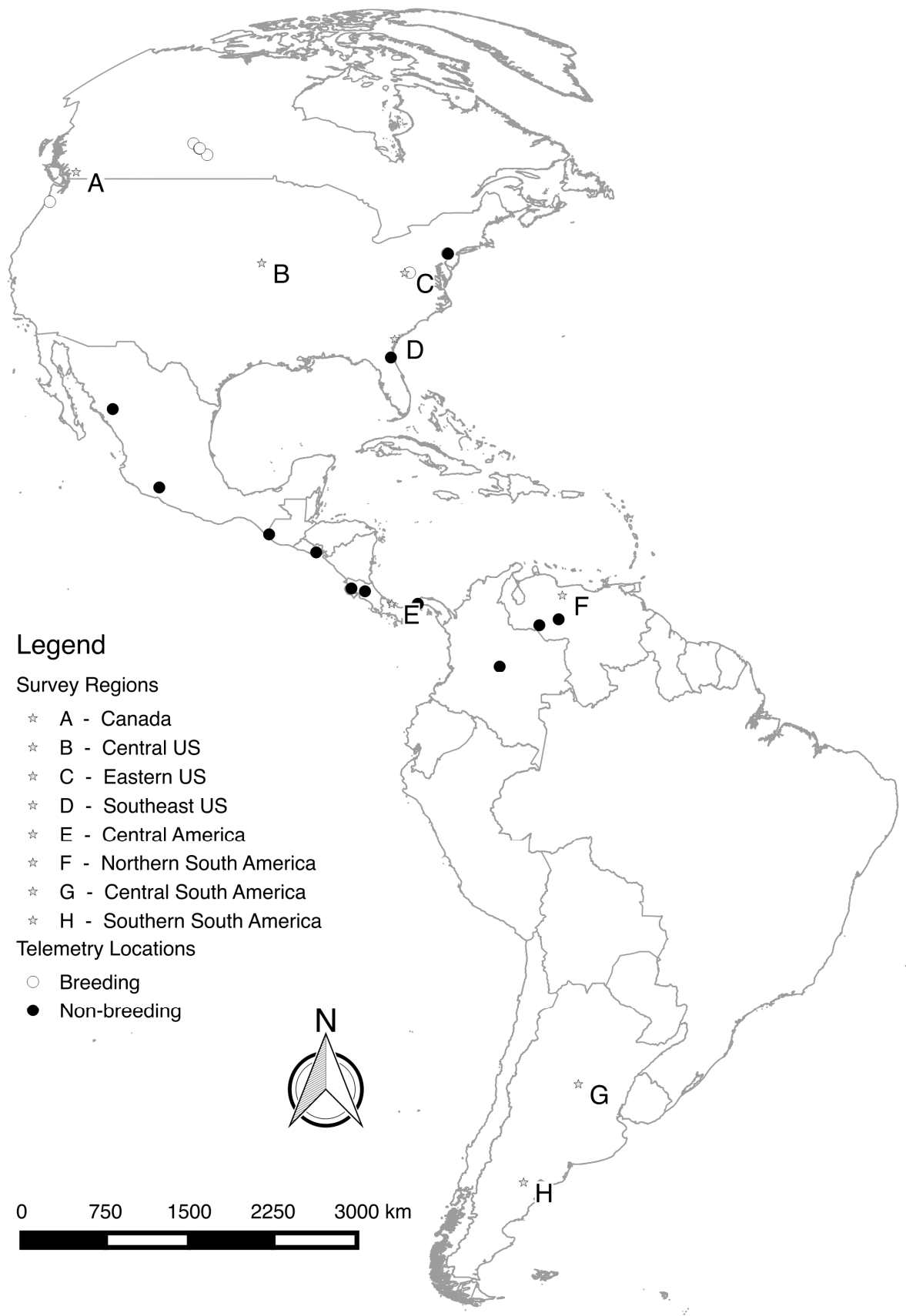

Fig. 2-1. Map of eight regions surveyed (letters) across the Americas and telemetered bird breeding (open-circle) and non-breeding (closed-circle) locations. Breeding and nonbreeding locations did not have to overlap with regions surveyed, but were included if geographically similar. 


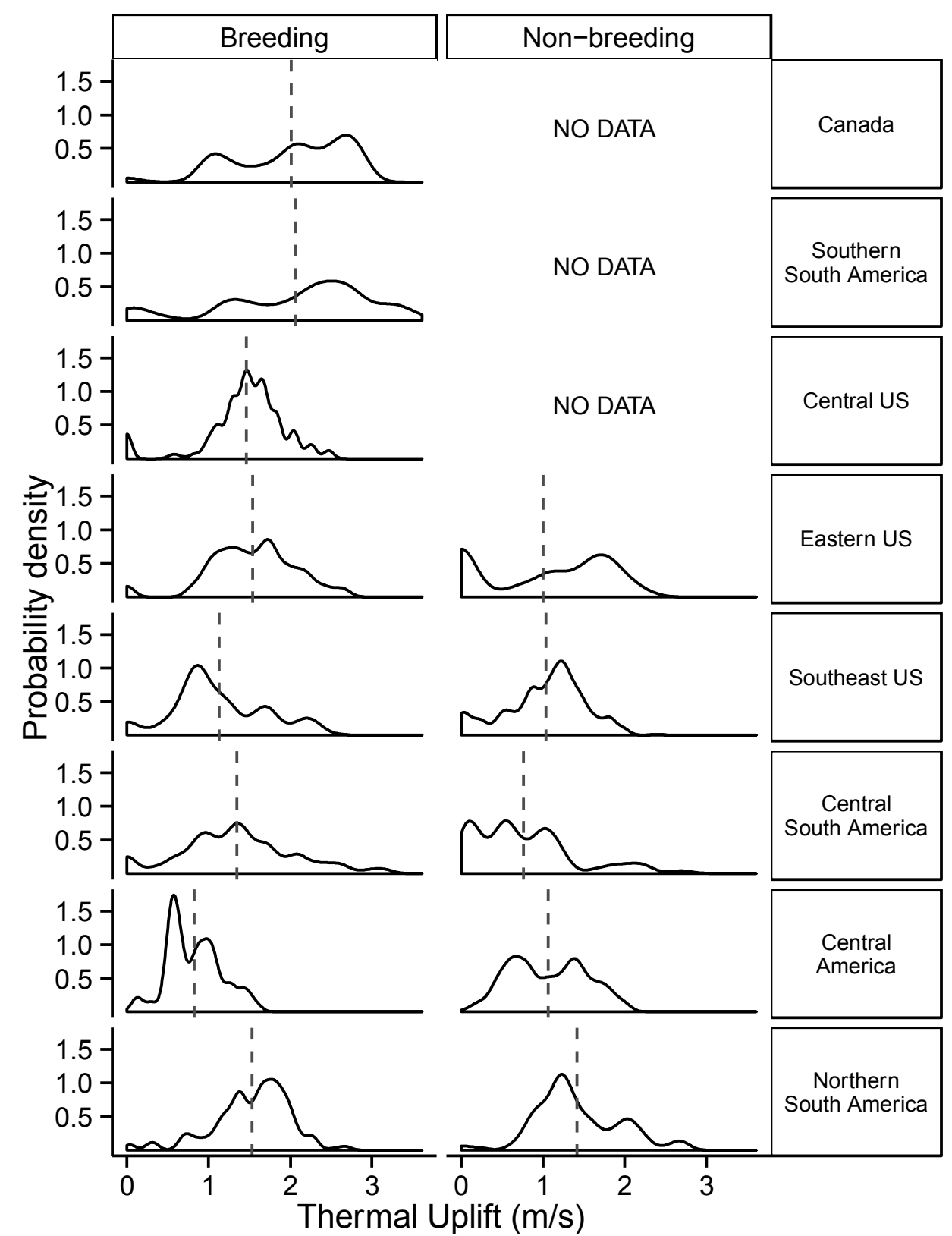

Fig. 2-2. Distribution of thermal uplift $(\mathrm{m} / \mathrm{s})$ in regions surveyed for vultures across the Americas. Regions are organized from highest to lowest in absolute latitude. Because some populations were obligate migrants, Canada, Southern South America, and Central US regions had no data during the non-breeding season. The dashed line indicates the mean uplift intensity. Thermal uplift is positively associated with absolute latitude during the breeding season and negatively associated with absolute latitude during the nonbreeding surveyed. 


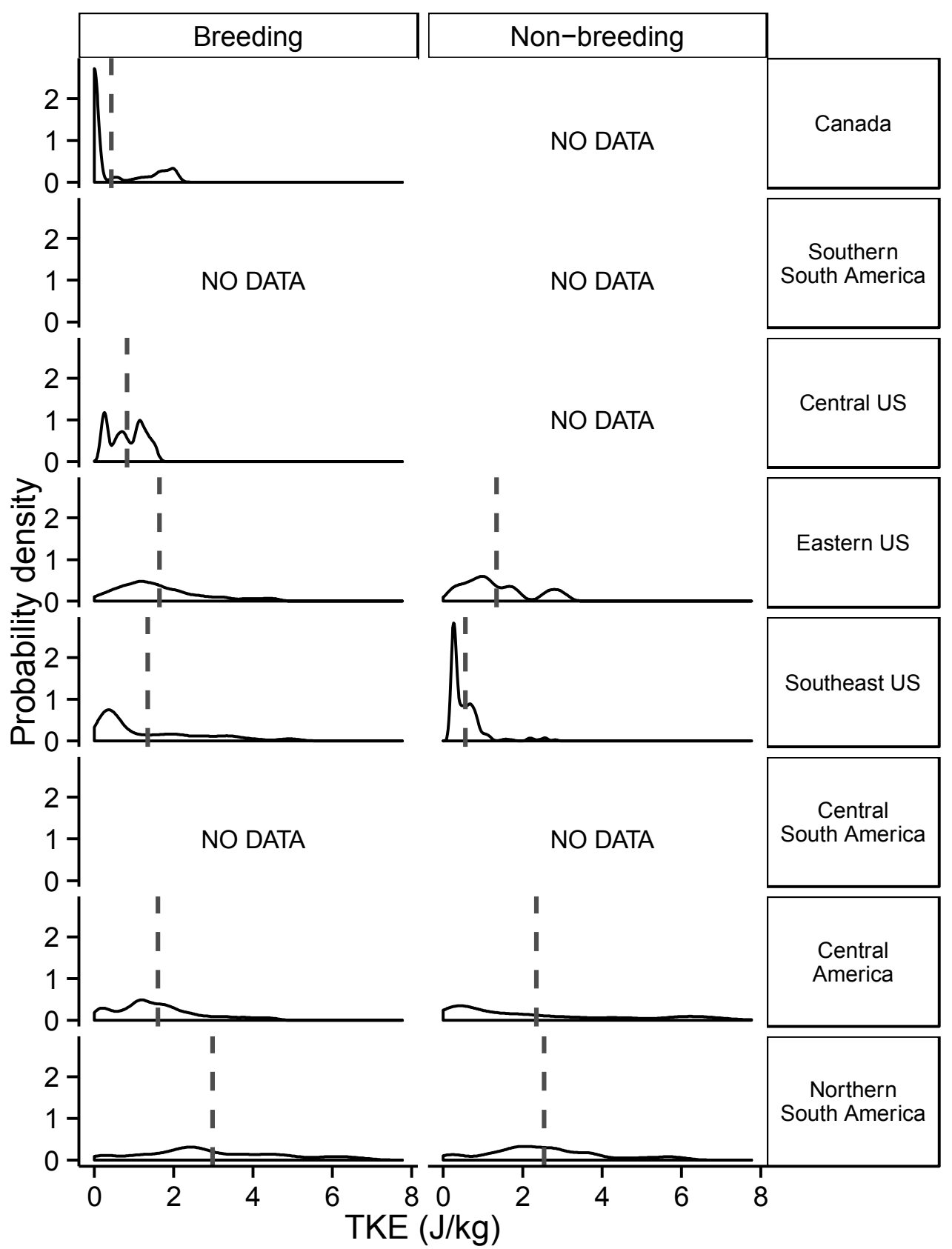

Fig. 2-3. Distribution of TKE (J/kg) (an indicator of turbulent uplift intensity) in regions surveyed for vultures across the Americas. Regions are organized from highest to lowest in absolute latitude. TKE data was only available for regions between $54 \mathrm{~N}-12 \mathrm{~N}$ and therefore unavailable in certain regions surveyed. The dashed line indicates the mean uplift intensity. Turbulent uplift is negatively associated with absolute latitude during both seasons. 


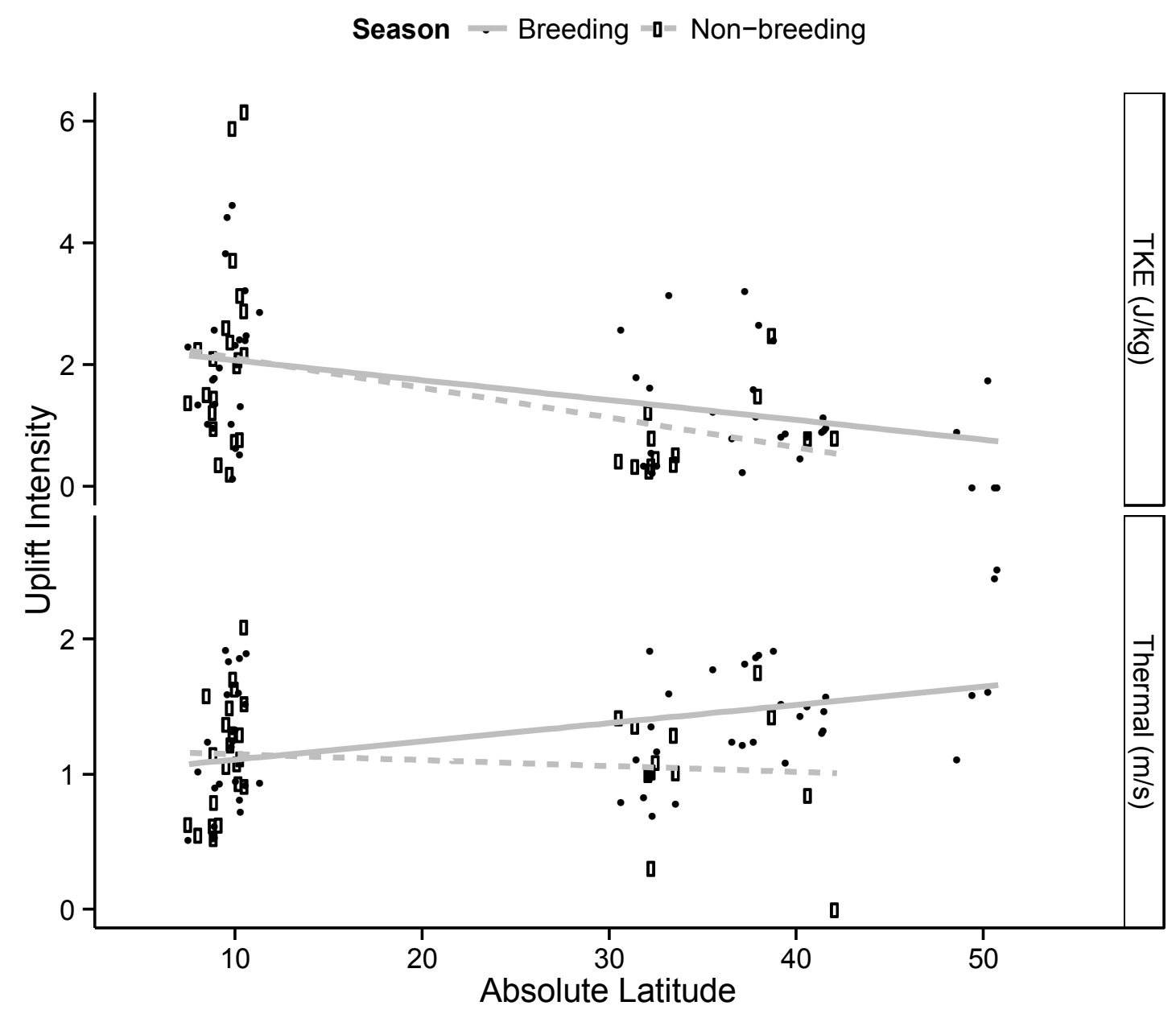

Fig. 2-4. Uplift intensities (TKE and thermal) at road survey locations versus absolute latitude. TKE $(\mathrm{J} / \mathrm{kg})$ intensity decreases with absolute latitude during both seasons. TKE intensity decreased slightly during the non-breeding season. Thermal uplift intensity increased with latitude during breeding seasons (April - September in northern hemisphere; November - March in southern hemisphere) but had no trend during nonbreeding season. 


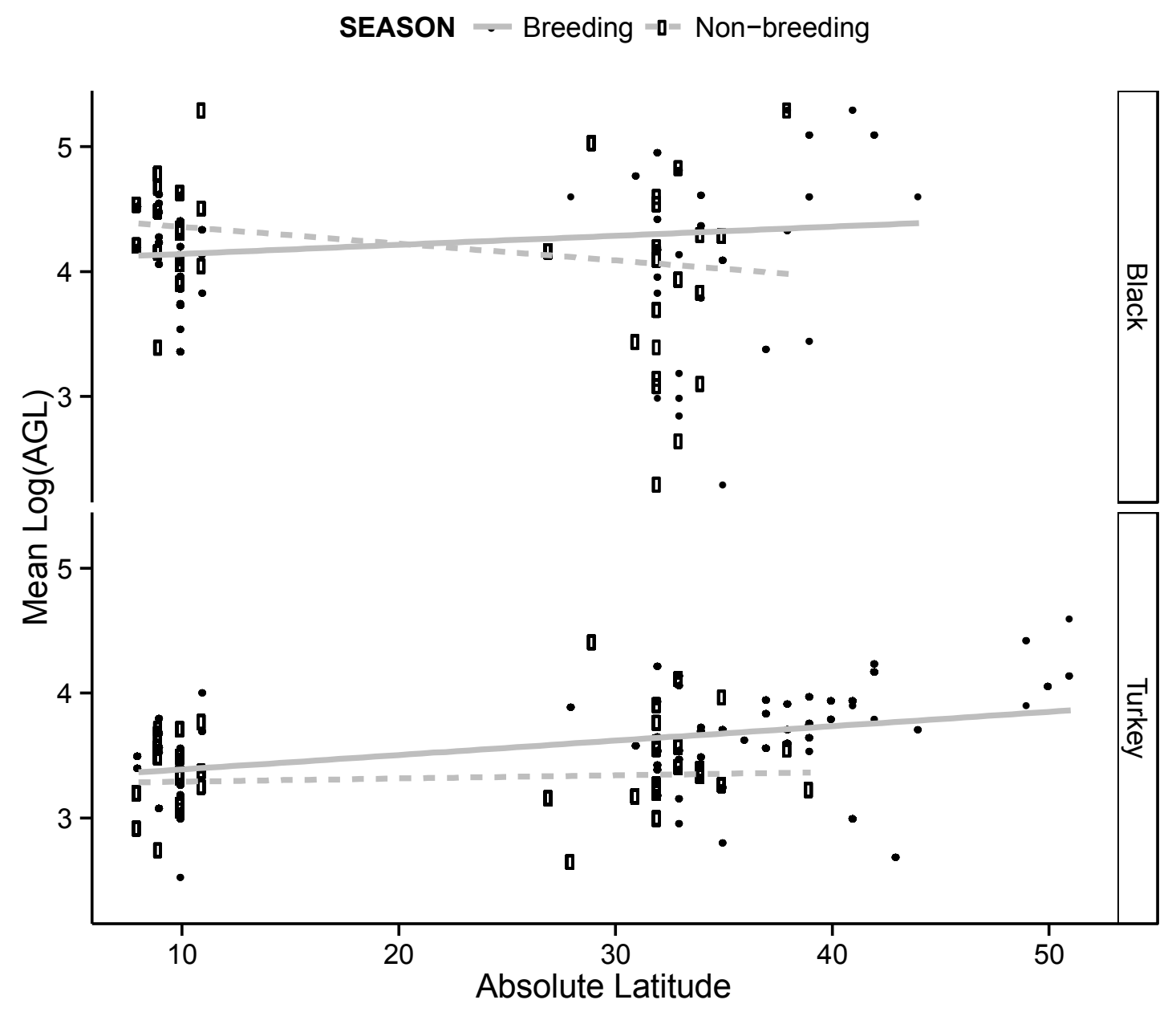

Fig. 2-5. Mean altitudes of black and turkey vulture flights $<200 \mathrm{~m}$ by absolute latitude. Log-transformed above ground level (AGL) altitudes were summarized by locale. Mean flight altitude increased slightly with latitude during the breeding season for both species. Black vultures low altitude flights did not respond to absolute latitude ( $p$-value $=0.855$ ). Turkey vulture low altitude flights did respond to absolute latitude ( $p$-value $=0.0103)$. 

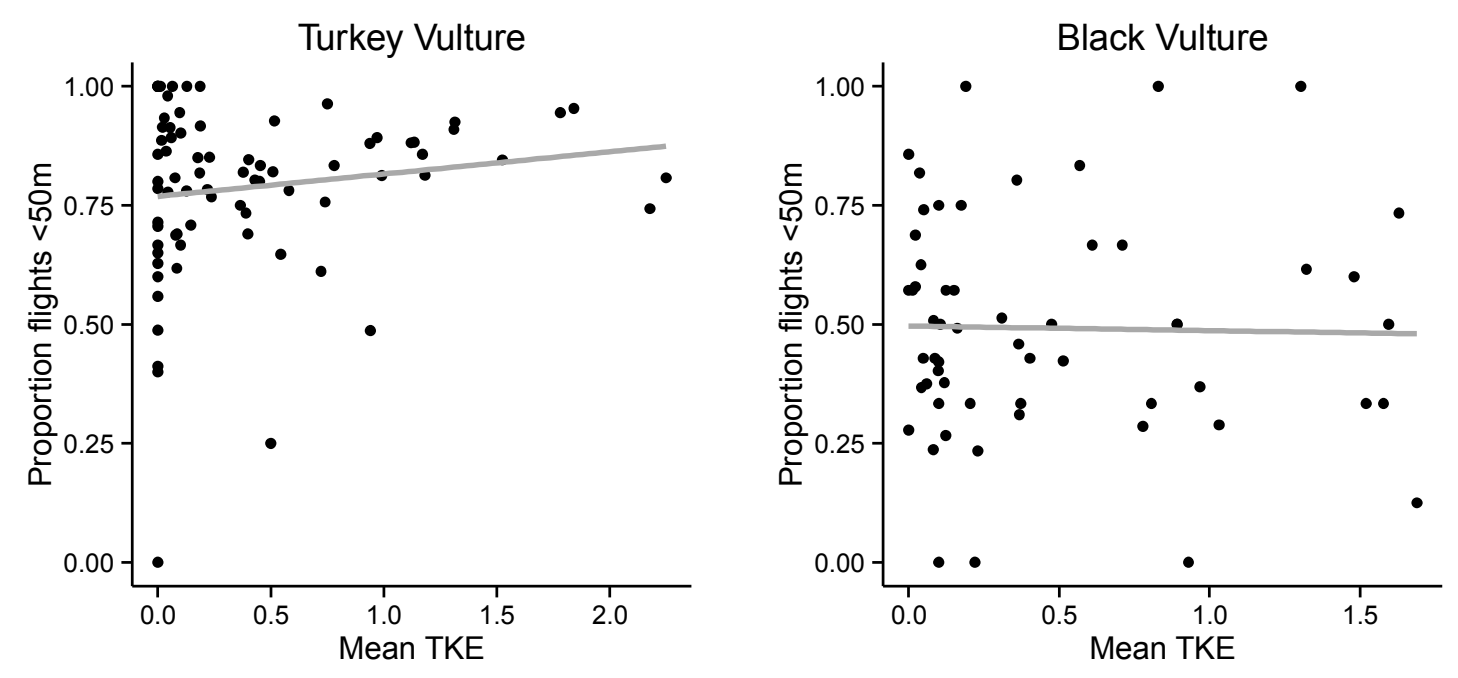

Fig. 2-6. Proportion of low altitude flights ( $<=50 \mathrm{~m} \mathrm{AGL}$ ) by turkey and black vultures versus mean TKE $(\mathrm{J} / \mathrm{kg})$ for each locale surveyed. Turkey vultures increased low altitude flights with increasing TKE intensity ( $p$-value=0.211). Black vulture low altitude flights had no response to TKE intensity ( $p$-value $=0.858)$. 


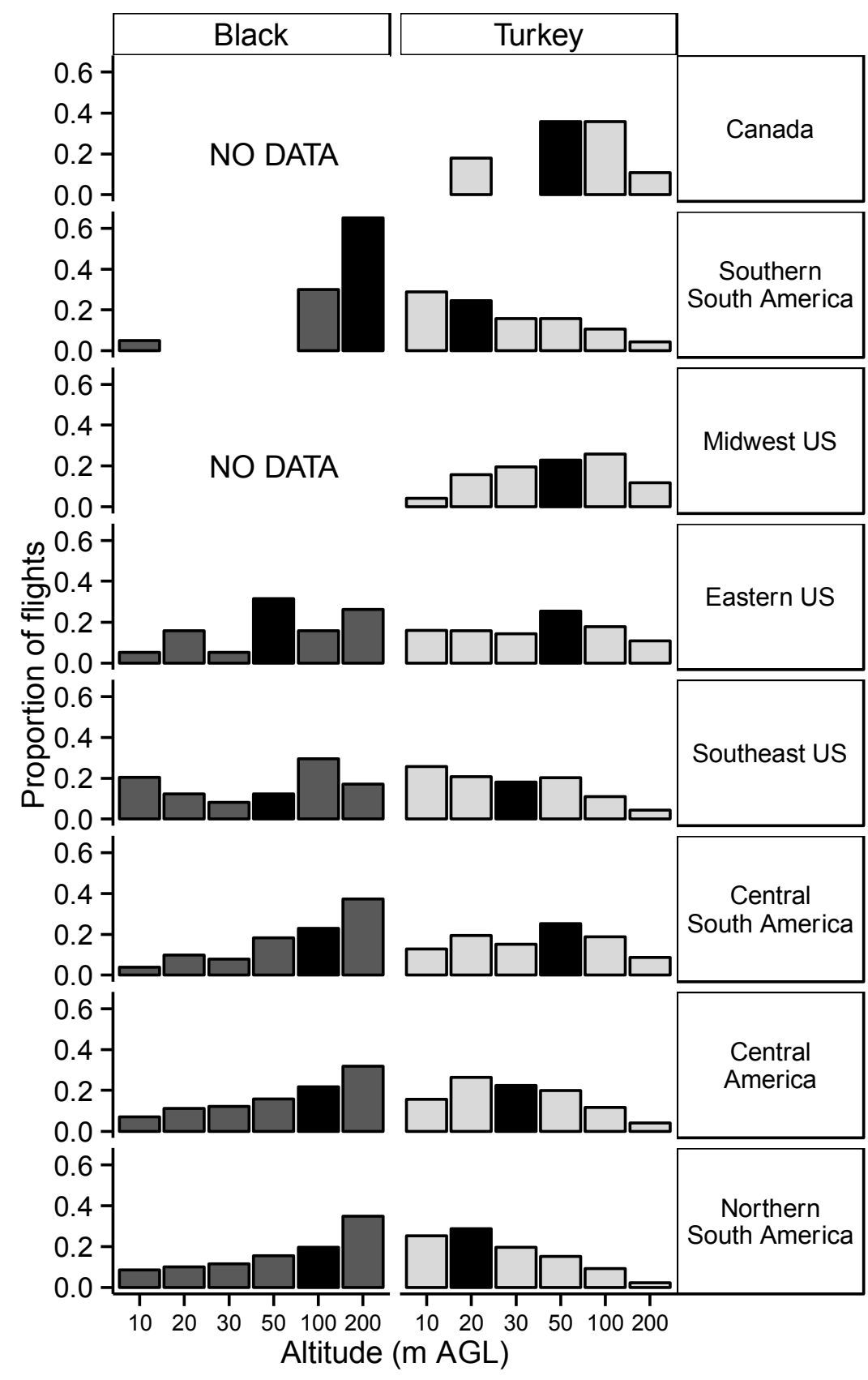

Fig. 2-7. Distribution of flight altitudes of surveyed vultures by region. Regions are organized (top to bottom) furthest from the equator to closest to the equator. Vultures were categorized as $<10,11-20,21-30,31-50,51-100$, or 101-200 $\mathrm{m}$ above ground level (AGL). Black bar indicates median flight altitude. Black vultures (left column) were absent from Canada and Midwest US. Black vultures consistently flew higher than turkey vultures. 